\title{
In Situ Immobilized Sesamol-Quinone/Carbon Nanoblack-Based Electrochemical Redox Platform for Efficient Bioelectrocatalytic and Immunosensor Applications
}

\author{
Mansi Gandhi, ${ }^{\dagger}$ Desikan Rajagopal, ${ }^{*}{ }^{\dagger}, \perp$ Sampath Parthasarathy, ${ }^{\perp}$ Sudhakaran Raja, ${ }^{\S}$ \\ Sheng-Tung Huang, ${ }^{\| \odot}$ and Annamalai Senthil Kumar*, ${ }^{*}, \|_{\odot}$
}

${ }^{\dagger}$ Nano and Bioelectrochemistry Research Laboratory, Department of Chemistry, School of Advanced Sciences, ${ }^{\ddagger}$ Carbon dioxide Research and Green Technology Centre, and ${ }^{\S}$ Aquaculture Biotechnology Laboratory, Department of Integrative Biology, School of Biosciences and Technology, Vellore Institute of Technology, Vellore 632014, India

"Institute of Biochemical and Biomedical Engineering, National Taipei University of Technology, Taipei 10608, Taiwan, ROC

${ }^{\perp}$ Burnett School of Biomedical Sciences, College of Medicine, University of Central Florida, Orlando, Florida 32827, United States

Supporting Information

\begin{abstract}
Most of the common redox mediators such as organic dyes and cyanide ligand-associated metal complex systems that have been used for various electrochemical applications are hazardous nature. Sesamol, a vital nutrient that exists in natural products like sesame seeds and oil, shows several therapeutic benefits including anticancer, antidiabetic, cardiovascular protective properties, etc. Herein, we introduce a new electrochemical redox platform based on a sesamol derivative, sesamol-quinone (Ses-Qn; oxidized sesamol), prepared by the in situ electrochemical oxidation method

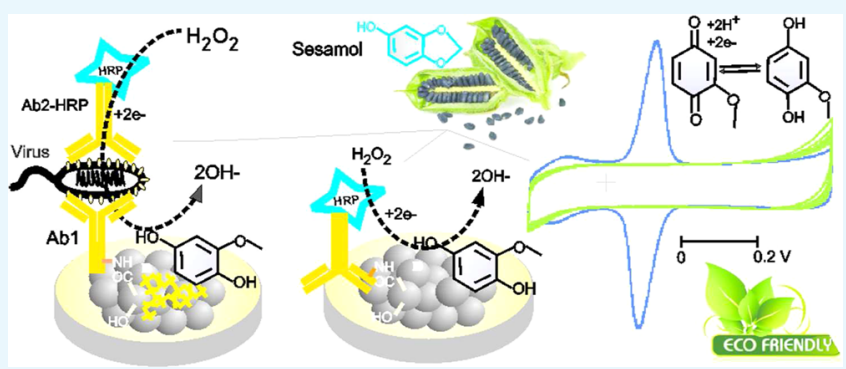
on a carbon nanoblack chemically modified glassy carbon electrode surface (GCE/CB@Ses-Qn) in pH 7 phosphate buffer solution, for nontoxic and sustainable electrochemical, electroanalytical, and bioelectroanalytical applications. The new Ses-Qnmodified electrode showed a well-defined redox peak at $E^{\mathrm{o}}=0.1 \mathrm{~V} \mathrm{vs} \mathrm{Ag} / \mathrm{AgCl}$ without any surface-fouling behavior. Following three representative applications were demonstrated with this new redox system: (i) simple and quick estimation of sesamol content in the natural herbal products by electrochemical oxidation on GCE/CB followed by analyzing the oxidation current signal. (ii) Utilization of the GCE/CB@Ses-Qn as a transducer, bioelectrocatalytic reduction, and sensing of $\mathrm{H}_{2} \mathrm{O}_{2}$ after absorbing the horseradish peroxidase (HRP)-based enzymatic system on the underlying surface. The biosensor showed a highly selective $\mathrm{H}_{2} \mathrm{O}_{2}$ signal with current sensitivity and detection limit values $0.1303 \mu \mathrm{A} \mu \mathrm{M}^{-1}$ and $990 \mathrm{nM}$, respectively, with tolerable interference from the common biochemicals like dissolved oxygen, cysteine, ascorbic acid, glucose, xanthine, hypoxanthine, uric acid, and hydrazine. (iii) Electrochemical immunosensing of white spot syndrome virus by sequentially modifying primary antibody, antigen, secondary antibody (HRP-linked), and bovine serum albumin on the redox electrode, followed by selective bioelectrochemical detection of $\mathrm{H}_{2} \mathrm{O}_{2}$.
\end{abstract}

\section{INTRODUCTION}

Searching of new redox-active organic molecules that are derived from natural resources for electrochemical applications is a recent trend in the sustainable and advanced electrochemical research area. ${ }^{1-5}$ In this context, nonhazardous and ecofriendly redox-active molecules are pressingly needed for pollution-free electrochemical applications. Most often, redox systems such as quinone, ${ }^{2,4}$ organic dyes, ${ }^{6-9}$ metals, ${ }^{10-12}$ metal oxides, ${ }^{13-15}$ complexes like $\mathrm{Fe}(\mathrm{CN})_{6}{ }^{3-16-19}$ and organometallic systems like ferrocene and its derivatives ${ }^{19-21}$ have been used as homogeneous/heterogeneous mediators for various electrochemical, electro-organic, and electroanalytical applications. Indeed, these redox chemicals have been considered as hazardous, toxic, and environment polluting substances. ${ }^{22-27}$ For instance, hydroquinones are reported to be hematotoxic and carcinogenic agents associated with malignancy in occupational environments. ${ }^{28-30}$ Similarly, ferricyanide, which is a benchmark redox system, releases the deadly toxic hydrogen cyanide gas when exposed to an acidic environment. $^{31,32}$ Even ferrocene complex exposure led to cirrhotic changes in liver, affecting erythrocytes in animals. ${ }^{33}$ Thus, environmental impacts have become a major factor that discourage the use of the above-mentioned common redox systems. On the other hand, redox-active systems derived from natural resources such as herbs, phytochemicals, and spices have now gained recognition as an environmentally benign and sustainable system in electrochemistry. ${ }^{34,35}$ Nevertheless, the reported natural redox systems such as curcumin-quinone,

Received: June 10, 2018

Accepted: August 22, 2018

Published: September 7, 2018 
Scheme 1. Illustration of the in Situ Electrochemical Preparation and Redox Activity of Ses-Qn on glassy carbon electrode (GCE)/CB (A-C), Ab2-HRP-Modified GCE/CB@Ses-Qn and Its Bioelectrocatalytic $\mathrm{H}_{2} \mathrm{O}_{2}$ Reduction Reaction (D), and Electrochemical Immunosensor for WSSV via Bioelectrocatalytic Reduction of $\mathrm{H}_{2} \mathrm{O}_{2}(\mathrm{D}-\mathrm{F})^{a}$

Electrochemical Immunosensor:

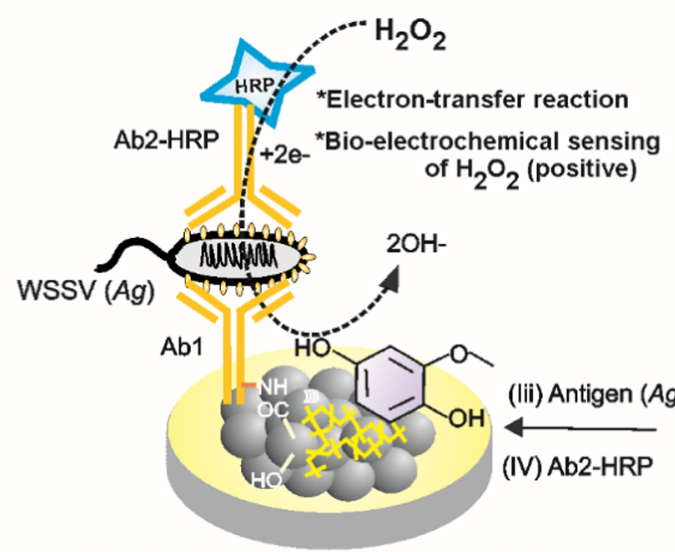

\section{F. GCE/CB@Ses-Qn/Ab1 (BSA)-Ag/Ab2-HRP}

E. GCE/CB@Ses-Qn/Ab1-BSA

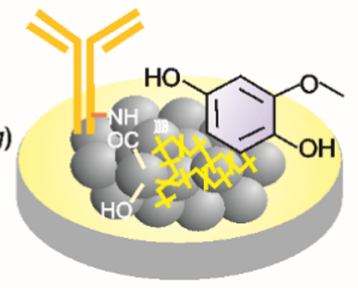

(li) BSA blocking
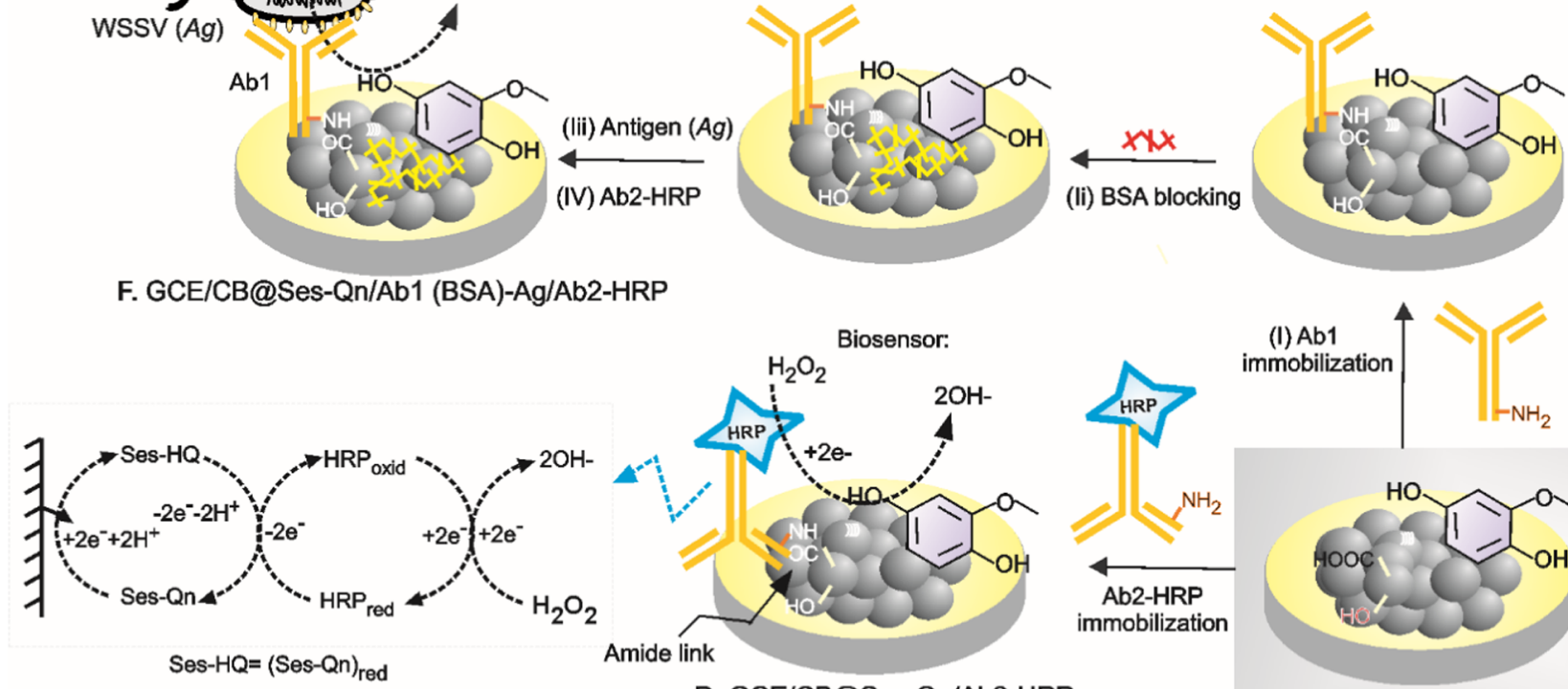

Amide lin

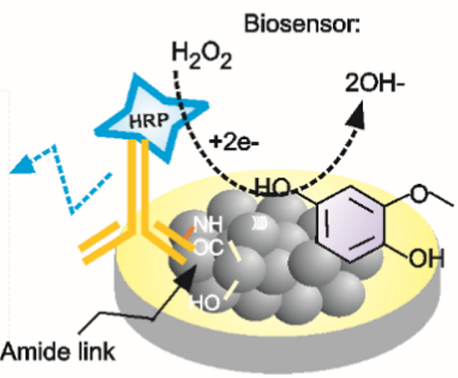

D. GCE/CB@Ses-Qn/Ab2-HRP
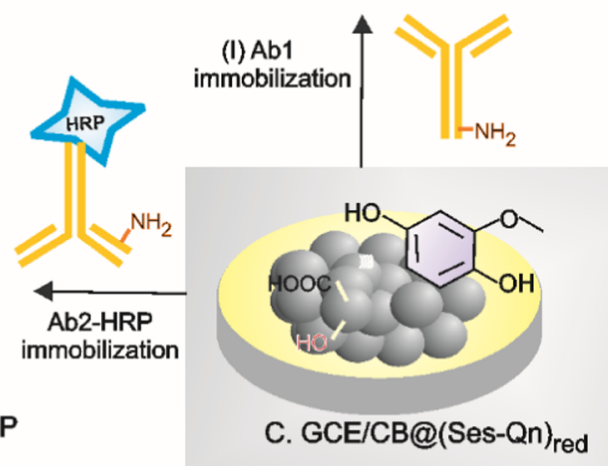

Sesamol

Intermediate

Sesamol-Quinone (Ses-Qn)<smiles>[R]P[14CH]CO/C(C)=C/C(C)=O</smiles>

nfirmation

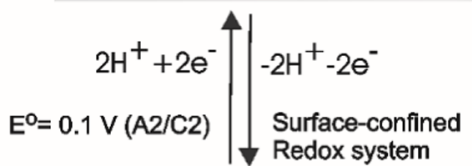

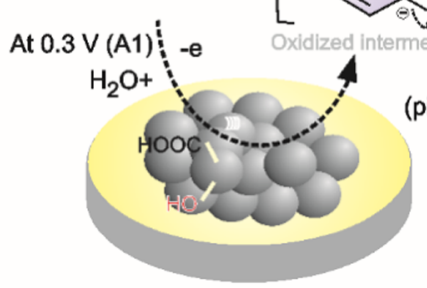

A. GCE/CB

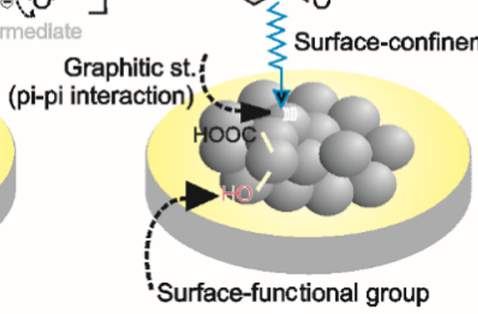

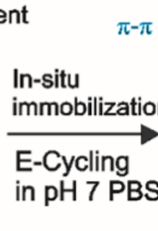

E-Cycling
in pH 7 PBS

${ }^{a}$ Inset is the plausible electron-transfer shuttling reaction scheme.

gingerol, and quercitin have been restricted for simple electrochemical oxidation and reduction reactions. ${ }^{36,37}$ The complexity and electroinactive character of natural products are the major limitations. Herein, we report a highly stable, ecofriendly, and biocompatible redox-active sesamol derivative, sesamol-1,4-quinone (Ses-Qn), prepared by in situ electrochemical oxidation of sesamol on an abundant carbon nanoparticle material, carbon black, as a surface-confined system (GCE/CB@Ses-Qn) for bioelectrocatalytic reduction of hydrogen peroxide and electrochemical immunosensing of white spot syndrome virus (WSSV) applications.

Sesamol (3,4-methylenedioxyphenol), a vital herb obtained from sesame seeds, ${ }^{38,39}$ has been used as a phytonutrient and shows ayurvedic medicinal activities like antioxidant, ${ }^{40,41}$ antifungal, $^{42}$ antidiabetic, ${ }^{43}$ anticancer, ${ }^{44,45}$ cardioprotective, ${ }^{46}$ etc. There have been some reports related to the electrochemical activity of the phenolic site in sesamol like electrochemical oxidation and antioxidant studies in acidic or semiaqueous $\left(\mathrm{CH}_{3} \mathrm{CN}+\mathrm{H}_{2} \mathrm{O}\right)$ medium. ${ }^{47,48}$ In this work, an effort has been made to convert sesamol as a surface-confined redox-active compound, Ses- $Q n$, on the CB material surface. The new Ses-Qn-modified electrode system showed a welldefined redox peak at an apparent standard electrode potential, $E^{\mathrm{o} \prime}=0.1 \mathrm{~V}$ vs $\mathrm{Ag} / \mathrm{AgCl}$, in $\mathrm{pH} 7$ phosphate buffer $(\mathrm{PB})$ solution corresponding to the electron-transfer reaction of the quinone derivative of sesamol (Ses-Qn). It has been identified that the oxidative cleavage of the methylene dioxo bridge in sesamol followed by generation of new redox-active quinone has occurred in a new electrochemical preparation step adopted in this work (Scheme 1). The NMR spectroscopic 
technique has been used to identify the critical functional group transformation that has occurred in situ on the electrode surface. It is noteworthy that the core structure of Ses-Qn resembles the structure of some of the natural products, for example, 2-methoxy-6-heptyl-1,4-benzoquinone and 2-methoxy-6-pentyl-1,4-benzoquinone, 5-(1,1-dimethylprop-2enyl)-2-(3-methylbut-2-enyl), and cyclohexa-2,5-diene-1,4dione that are isolated from Miconia lepidota leaves and New Zealand brown alga Perithalia capillaris. ${ }^{49}$ The present work covers the preparation, physicochemical characterization, and three different electrochemical applications of the sesamol redox coupled modified electrode. These applications include (i) selective detection of sesamol content in sesame seeds (black seed, \#1 and white seed, \#2) and oils (\#3-\#5); (ii) biocatalytic reduction and sensing of $\mathrm{H}_{2} \mathrm{O}_{2}$ utilizing the horseradish peroxidase (HRP)-based enzyme system immobilized electrode; and (iii) analysis of electrochemical immunosensing of white spot syndrome virus (WSSV), by integrating with the primary (Ab1) and secondary (Ab2-HRP) antibodies on the electrode surface.

For biosensing of hydrogen peroxide, in general, redox mediators like methylene blue and ferricyanide (Zobell solution) coupled with the HRP enzyme and Au nanoparticles have been frequently used. ${ }^{50-54}$ Unfortunately, complicated preparation procedures and use of hazardous (conventional redox systems) and expensive chemicals (Au nanoparticles) restrict the assays for further applications. Note that the covalent linkers such as 1-ethyl-3-(3-dimethylaminopropyl)carbodiimide $\mathrm{N}$-hydroxysulfosuccinimide (EDC-NHS) have been widely adopted for covalent linkage of amino and carboxylic functional groups on the modified electrode surface. ${ }^{50,51,54}$ Furthermore, the functionalization procedure takes about $3-6 \mathrm{~h}$ of working time to complete the reaction. ${ }^{55}$ In this work, we simplified the procedure and immobilized the antibody without any EDC-NHS linker on the GCE/CB@SesQn.

White spot syndrome virus (WSSV) is one of the devastating viral infections in penaeid shrimp. ${ }^{50,56}$ It creates huge loss to the aquaculture industry. Early detection of the virus by quick and simple analytical methodology is direly needed to save from the loss. Conventionally, the polymerase chain reaction, gene therapy, and DNA microarray methods have been frequently used for the detection of WSSV (vp28 protein). ${ }^{57-59}$ Unfortunately, the assays are less sensitive, require several offline sample preparations, and involve hazardous chemicals (ethylene bromide) and time-consuming procedures $(\sim 12 \mathrm{~h})$. Alternately, the electrochemical platform provides a wonderful tool for the development of electronicgadget-based biosensor systems. Previously, our group demonstrated the methylene blue dye-based electrochemical immunosensor assay for the WSSV. ${ }^{46}$ In this work, GCE/CB@ Ses-Qn has been used as a transducer to study the electrochemical immunosensing of WSSV. Note that CB is an ultra-low-cost carbon material that has been prepared as a bulk from hydrocarbons (oil and natural gas) and used as an ingredient in the tyre industry. ${ }^{60}$ The $\mathrm{CB}$ material is found to be optimal for the immobilization of Ses-Qn in this work.

\section{EXPERIMENTAL SECTION}

2.1. Materials. Carbon black (N330 grade) was obtained as a gift sample from Phillips Carbon Black Ltd. Kochi, India. Sesamol ( $\sim 95 \%$ purity), activated carbon (99.95\%), carboxylic acid-functionalized multiwalled carbon nanotube (f-MWCNT,
$>80 \%$ carbon basis; >8\% carboxylic acid functionalization), MWCNT ( $~ 95 \%$ purity assay; outer diameter size, $10-15 \mathrm{~nm}$; inner diameter size, 2-6 nm; length, 0.1-10 $\mathrm{mm}$ ), singlewalled carbon nanotube (SWCNT; $70 \%$ purity on carbon basis, size 0.7-1.1 nm diameter), double-walled carbon nanotube (DWCNT; 50-80\% carbon basis), bovine serum albumin (BSA), and graphene oxide (GO)-ethanol dispersed stock solution $\left(5 \mathrm{mg} \mathrm{mL}^{-1}, \sim 80 \%\right.$ carbon basis; flake size, $0.5-$ $2.0 \mu \mathrm{m}$; thickness, $0.6-1.2 \mathrm{~nm}$; purity, 99\%) were all purchased from Sigma-Aldrich. Anhydrous sodium dihydrogen phosphate ( $\geq 98 \%$ purity) and anhydrous disodium hydrogen phosphate ( $\geq 98 \%$ purity) were obtained from Merck, Germany. The $\mathrm{pH} 7$ phosphate buffer (PB) solution of 0.1 $M$ ionic strength was used as a supporting electrolyte throughout this study. Sesame seeds of black (\#1) and white (\#2) varieties and different brands of sesame oils (\#3-\#5) were collected from a local supermarket at Vellore. The WSSV gene (vp28) was obtained from Xcelris, India. The secondary antibody (Ab2-HRP conjugate; goat-raised anti-rabbit) was obtained from Genei, Bangalore, India. The primary antibody, anti-mouse vp28 polyclonal antibody (raised in rabbit), was obtained as a gift from Professor A. S. Sahul Hameed, Abdul Hakeem College, India. The aqueous solutions were prepared using double-distilled water. Because dissolved oxygen is not interfering, no effort is made to remove oxygen from the test solution.

2.2. Apparatus. Cyclic voltammetry (CV) measurements were carried out with a $\mathrm{CHI}$ model $660 \mathrm{C}$ electrochemical workstation. The conventional three-electrode system consisted of the glassy carbon electrode (GCE; $0.0707 \mathrm{~cm}^{2}$ area) and its chemically modified electrode as a working electrode, $\mathrm{Ag} / \mathrm{AgCl}$ (in $3 \mathrm{M} \mathrm{KCl}$ ) as a reference electrode, and platinum as a counter electrode using $10 \mathrm{~mL}$ working volume. Fourier transform infrared (FTIR) spectroscopic measurements were performed using a JASCO 4100 instrument (Japan) with $\mathrm{KBr}$. The proton NMR was recorded on Bruker $400 \mathrm{MHz}$ using $\mathrm{CDCl}_{3}$ as a solvent.

2.3. Sesamol-Quinone-Modified Electrode Preparation. First, GCE was cleaned and polished using an alumina powder kit, followed by electrochemical pretreatment (in a window of $-0.2-1.2 \mathrm{~V}$ vs $\mathrm{Ag} / \mathrm{AgCl}$ at a scan rate (v) of $50 \mathrm{mV}$ $\mathrm{s}^{-1}$ for 20 cycles) in $\mathrm{pH} 7 \mathrm{~PB}$ solution. Five microliters of $3 \mathrm{mg}$ CB-dispersed ethanol $(1 \mathrm{~mL})$ was drop-casted on the GCE surface and left for drying for about $2 \pm 1 \mathrm{~min}$ at room temperature $\left(25{ }^{\circ} \mathrm{C}\right)$. Then, the GCE/CB@Ses-Qn-modified system was prepared by $\mathrm{CV}$ potential cycling of $\mathrm{GCE} / \mathrm{CB}$ in a dilute $(100 \mu \mathrm{M})$ sesamol dissolved $\mathrm{pH} 7 \mathrm{~PB}$ solution in a window of $-0.2-0.6 \mathrm{~V} \mathrm{Ag} / \mathrm{AgCl}$ continuously for 20 cycles at $\mathrm{v}=50 \mathrm{mV} \mathrm{s}^{-1}$. In a similar way, other carbon nanomaterialmodified Ses-Qn samples were prepared

2.4. Sampling of Sesame Seeds and Oils. Briefly, $10 \mathrm{mg}$ of weighed seeds and oils placed separately in a round bottom flask containing $40 \mathrm{~mL}$ of $\mathrm{MeOH}$ was subjected to refluxing with constant stirring for $\sim 120 \mathrm{~min}$ in an oil bath maintained at $T=55^{\circ} \mathrm{C} .{ }^{39-41}$ A yellowish methanol layer, which contains the sesamol compound, was filtered using Whatman Filter paper and subjected to electroanalysis after appropriate dilution in $\mathrm{pH} 7 \mathrm{~PB}$ solution by the standard addition method using the differential pulse voltammetric (DPV) technique. Following are the DPV conditions: initial potential $=0.0 \mathrm{~V}$; final potential $=0.8 \mathrm{~V}$; increment potential $=0.004 \mathrm{~V}$; amplitude $=0.05 \mathrm{~V}$; pulse width $=0.2 \mathrm{~s}$; and pulse period $=0.5$ s. 
A.

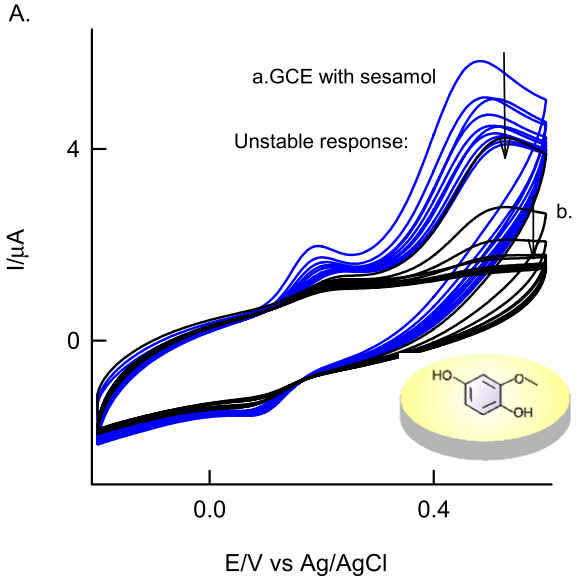

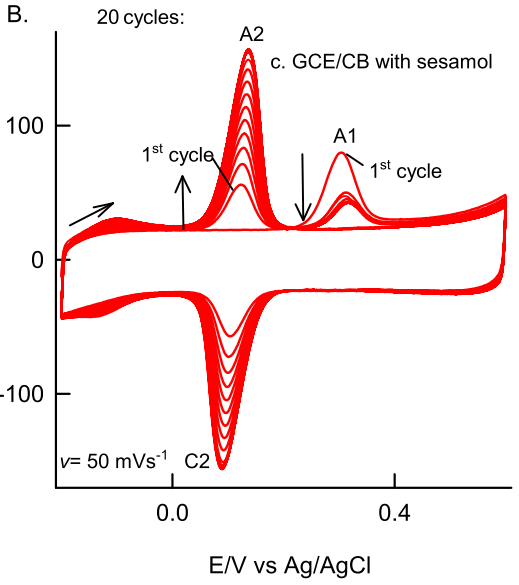

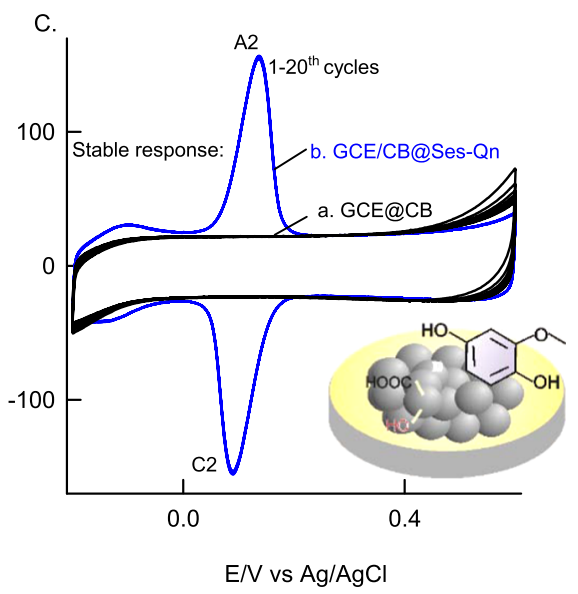

Figure 1. CV responses of (A) GCE with $100 \mu \mathrm{M}$ sesamol in $\mathrm{pH} 7 \mathrm{~PB}$ solution (curve a) and its medium transferred blank pH $7 \mathrm{~PB}$ solution (curve b), (B) GCE/CB with $100 \mu \mathrm{M}$ sesamol, and (C) its medium transferred blank pH 7 PB solution (curve a). Control CV of GCE/CB is shown in (C), curve c; $\nu=50 \mathrm{mV} \mathrm{s}^{-1}$. The inset in (C) is a cartoon for the GCE/CB@Ses-Qn. Note: Ses-Qn = Ses-Oxid.

A.

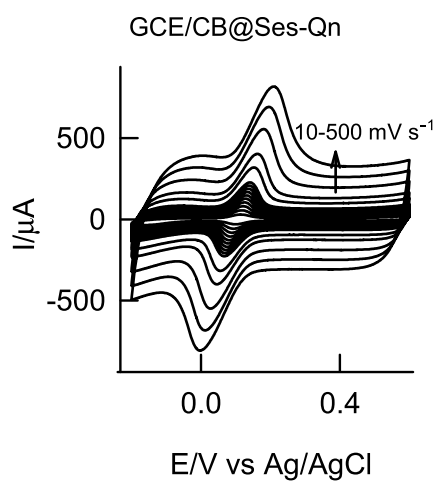

B.

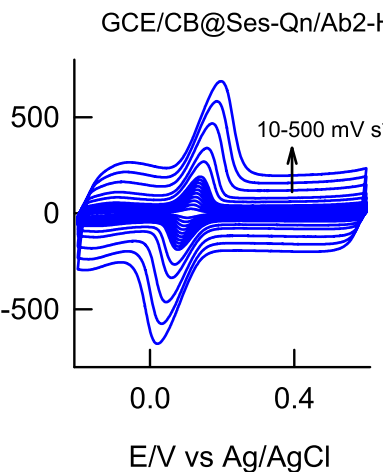

C.

D.

Figure 2. Effect of CV scan rate of GCE/CB@Ses-Qn (A) and GCE/CB@Ses-Qn/Ab2-HRP (B) in pH 7 PB solution and its typical $i_{\mathrm{pa}}$ and $i_{\mathrm{pc}}$ vs scan rate $(\mathrm{C})$ and $E_{\mathrm{pa}}$ and $E_{\mathrm{pc}}$ vs $\log \nu$ plots $(\mathrm{D})$. Note that Ses-Qn = Ses-Oxid.

2.5. Procedure for Electrochemical Immunosensing. Following is the stepwise procedure adopted for the analysis (Scheme $1 \mathrm{C}-\mathrm{F}$ ): step $1 ; 1 \mu \mathrm{L}$ of $\mathrm{Ab} 1$ from a stock solution, 1 $\mathrm{mg} \mathrm{mL} \mathrm{L}^{-1}$, was drop-casted directly on GCE/CB@Ses-Qn, followed by $1 \% \mathrm{w} / \mathrm{v}\left(1 \mathrm{mg}\right.$ in $\left.\mathrm{mL}^{-1}\right) \mathrm{BSA}$, and dried at room temperature $\left(25^{\circ} \mathrm{C}\right)$ for $5 \mathrm{~min}$. This electrode is denoted GCE/CB@Ses-Qn/Ab1-BSA. The BSA used here is to block the surface active-sites (which are nonspecific) to Ab1 to avoid false response. The above electrode was washed twice with double-distilled water to remove the excess primary antibody and BSA physisorbed on the electrode surface. Step 2; $1 \mu \mathrm{L}$ of antigen stock $\left([\mathrm{Ag}]=1.31 \times 10^{8}\right.$ copies $\left.\mu \mathrm{L}^{-1}\right)$ was coated, dried, and again washed (GCE/CB@Ses-Qn/Ab1-BSA-Ag). Step $3 ; 1 \mu \mathrm{L}$ of secondary antibody, which is a primaryantibody-linked HRP (Ab2-HRP) from the stock solution, 1 $\mathrm{mg}$ in $\mathrm{mL}^{-1}$, was coated on the electrode surface (GCE/CB@ Ses-Qn/Ab1-BSA-Ag-Ab2-HRP), dried at room temperature for $5 \mathrm{~min}$, and washed with double-distilled water to remove the excess Ab2-HRP. In total, 15 min time is required for the biosensor preparation. The above biosensor was subjected to $\mathrm{CV}$ study in the absence and presence of $500 \mu \mathrm{M} \mathrm{H}_{2} \mathrm{O}_{2}$ at $v=$ $10 \mathrm{mV} \mathrm{s}^{-1}$. Depending on the $\mathrm{Ag}$ concentration $\left(1.31 \times 10^{-3}\right.$ to $1.31 \times 10^{7}$ copies $\mu \mathrm{L}^{-1}$ ), variable $\mathrm{H}_{2} \mathrm{O}_{2}$ sensing currents were obtained. As controls, uninfected fish muscle and BF-2 (infectious pancreatic necrosis virus (IPNV) obtained from fish gills) were analyzed directly casting the crushed test sample on the sensor electrode in place of $\mathrm{Ag}$ in the electrochemical immunosensor preparation procedure. The preparation procedure of the control-modified electrode is similar to the GCE/CB@Ses-Qn-Ab1-BSA-Ag-Ab2-HRP procedure (Scheme 1).

\section{RESULTS AND DISCUSSION}

3.1. Electrochemical Response of Sesamol on GCE/ CB. The initial experiment was carried out using unmodified GCE with $100 \mu \mathrm{M}$ standard sesamol compound in $\mathrm{pH} 7 \mathrm{~PB}$ solution, as in Figure 1A, curve a. An unstable irreversible peak at the anodic side, $E_{\mathrm{pa}} 0.35 \mathrm{~V}$ (A1), followed by an unstable reversible peak at apparent standard electrode potential, $E^{\mathrm{o}^{\prime}}=$ $0.10 \mathrm{~V}$ vs $\mathrm{Ag} / \mathrm{AgCl}(\mathrm{A} 2 / \mathrm{C} 2)$, were noticed. After the experiment, when the working electrode was gently washed with the electrolyte, $\mathrm{CV}$ was performed in a blank $\mathrm{pH} 7 \mathrm{~PB}$ solution, and there was no marked current signal for the redox peaks noticed (Figure 1A, curve b). This result indicates the adsorptionless voltammetric response of sesamol on the GCE surface. When the same experiment was repeated on $\mathrm{GCE} / \mathrm{CB}$, as in Figure $1 \mathrm{~B}$, well-defined electrochemical signals corresponding to $\mathrm{A} 1$ and $\mathrm{A} 2 / \mathrm{C} 2$ peaks similar to those in the GCEsesamol case but with about $100 \times$ higher current signal were noticed. The A2/C2 current signal was found to be increased 
A.

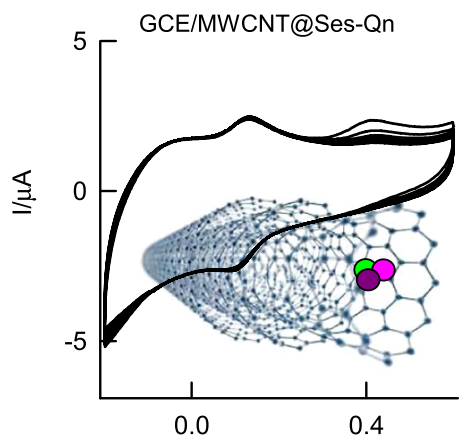

B.

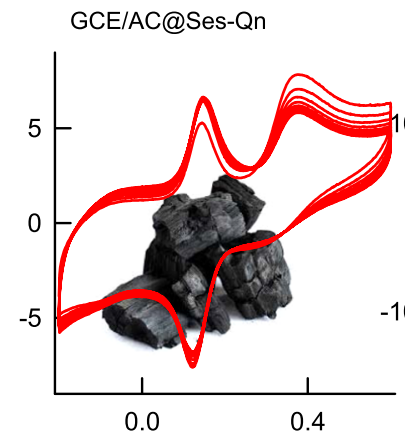

C.

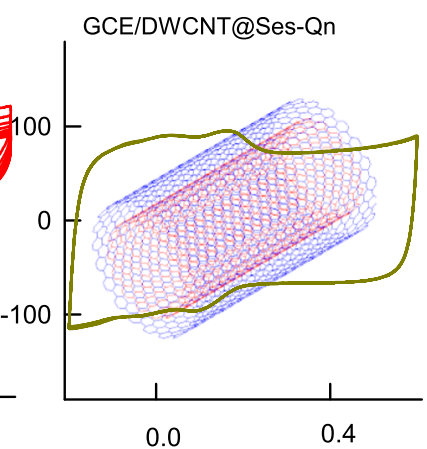

D.

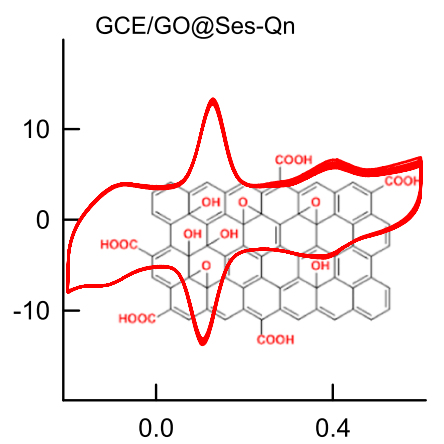

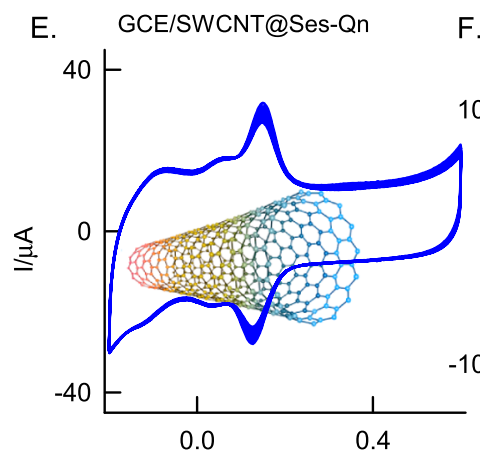

$\mathrm{E} / \mathrm{N}$ vs $\mathrm{Ag} / \mathrm{AgCl}$
F. GCE/f-WCNT@Ses-Qn

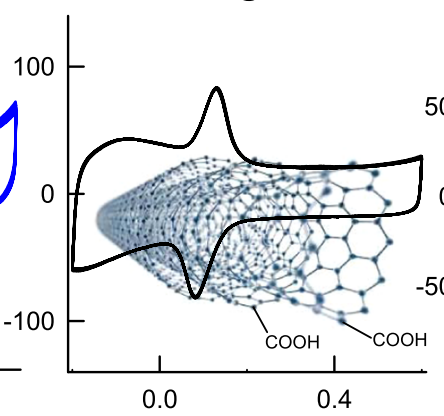

$\mathrm{E} / \mathrm{V}$ vs $\mathrm{Ag} / \mathrm{AgCl}$
G. GCE/CB@Ses-Qn H.

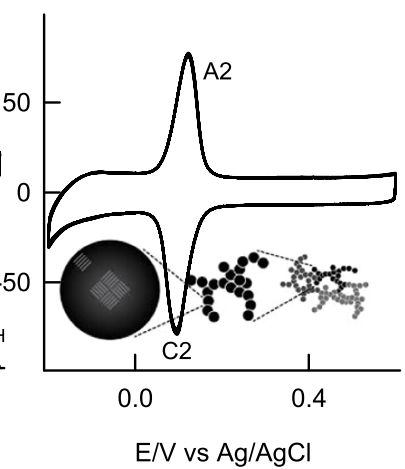

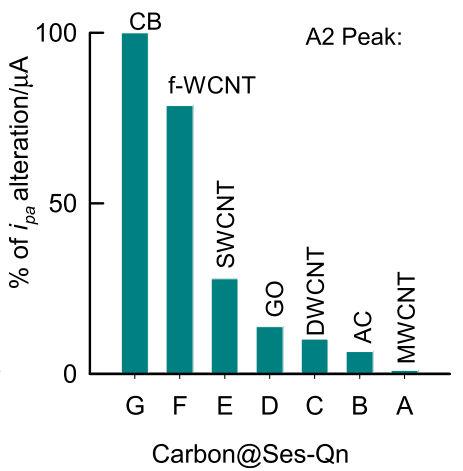

Figure 3. (A-H) CV responses of Ses-Qn-immobilized various carbon-modified GCEs (GCE/carbon@Ses-Qn) in pH 7 PB solution at $\nu=50 \mathrm{mV}$ $\mathrm{s}^{-1}$. Plot of $\%$ of $i_{\mathrm{pa}}$ alteration vs carbon@Ses-Qn. Note that Ses-Qn = Ses-Oxid. MWCNT = multiwalled carbon nanotube; AC = activated charcoal; DWCNT = double-walled carbon nanotube; GO = graphene oxide; SWCNT = single-walled carbon nanotube; $\mathrm{f}-\mathrm{MWCNT}=$ carboxylic acid-functionalized MWCNT; CB = carbon nanoblack.

with cycle number up to 20 , followed by saturation in the response, whereas the Al peak signal was diminished in the second cycle and get saturated. Interestingly, when the above working electrode was medium transferred to a blank $\mathrm{pH} 7 \mathrm{~PB}$ solution and $\mathrm{CV}$ was performed, as in Figure $1 \mathrm{C}$, curve $\mathrm{b}$, the A2/C2 redox peak was found to be retained with a relative standard deviation (RSD) of $1.3 \%(n=20)$, indicating good stability of the chemically modified electrode. There was no sign of the Al signal on the modified electrode surface. The peak-to-peak potential difference was calculated as follows, $\Delta E_{\mathrm{p}}=E_{\mathrm{pa}}-E_{\mathrm{pc}}$, wherein $E_{\mathrm{pa}}$ and $E_{\mathrm{pc}}$ are anodic and cathodic peak potentials, respectively, and surface excess $(\Gamma)$ values are $50 \pm 2 \mathrm{mV}$ and $58.37 \times 10^{-9} \mathrm{~mol} \mathrm{~cm}^{-2}$, respectively. The effect of scan rate on the redox peak showed a regular increase in the peak current signals, as in Figure 2A. Plots of $i_{\mathrm{pa}}$ and $i_{\mathrm{pc}}$ versus scan rate were nearly linear, suggesting surface-confined electron-transfer behavior of the modified electrode (Figure 2C). Applying the Laviron theory under the condition $\Delta E_{\mathrm{p}}<$ $200 \mathrm{mV}$ (Figure 2D), ${ }^{61}$ the heterogeneous electron-transfer rate constant, $k_{s}$, was calculated using the following equation, $m=(R T / F)\left(k_{\mathrm{s}} / n \nu\right)$, where $F$ is Faraday's constant, $96500, R$ is the gas constant $8.314, n$ is the number of electrons in the ratedetermining step, $\nu$ is the scan rate in $\mathrm{V} \mathrm{s}^{-1}$, and $T$ is $298 \mathrm{~K}$, and was found to be $1.75 \mathrm{~s}^{-1}$ at $\nu=100 \mathrm{mV} \mathrm{s}^{-1}$ and $\Delta E_{\mathrm{p}}=63$ $\mathrm{mV}$ (transfer coefficient, $\alpha=0.5$ ). The obtained $k_{\mathrm{s}}$ value is nearly equal to the values reported for the hemoglobin enzyme and metal complex-modified electrodes, $0.28 \mathrm{~s}^{-1}$ (MWCNTFe: $\mathrm{NH}_{2}$-chitosan for $\mathrm{H}_{2} \mathrm{O}_{2}$ reduction) ${ }^{62}$ and $1.21 \mathrm{~s}^{-1}$ (metalporphyrin-based biomimetic system for $\mathrm{H}_{2} \mathrm{O}_{2}$ reduction). On the basis of the electrochemical observation, it can be speculated that the oxidized species of sesamol (Ses-Oxid) gets immobilized on the GCE/CB and shows the surfaceconfined redox peak in this work. The modified electrode is tentatively denoted as GCE/CB@Ses-Oxid.

3.2. Effect of Carbon Nanomaterial on the Electrochemical Response of Sesamol. Aiming at understanding the effect of surface on Ses-Oxid formation, various carbon nanomaterials like graphene oxide, single-walled carbon nanotube (SWNT), double-walled carbon nanotube (DWCNT), MWCNT, and carboxylic acid-functionalized MWCNT (f-MWCNT) were examined for sesamol electrochemical reaction (i.e., GCE/carbon@Ses-Oxid), as in Figure $3 \mathrm{~A}-\mathrm{G}$. The experiments were conducted similar to Figure $1 \mathrm{~A}, \mathrm{~B}$. In all of the modified electrode cases, qualitatively similar voltammetric redox peak response at $E^{\circ \prime}=\sim 0.1 \pm 0.01 \mathrm{~V}$ vs $\mathrm{Ag} / \mathrm{AgCl}$ was noticed. With respect to the relative $\mathrm{A} 2$ peak current value, the order of sesamol immobilization on the carbon nanomaterials can be sequenced as follows: $\mathrm{CB}>\mathrm{f}$ MWCNT > SWCNT > GO > DWCNT > activated charcoal (AC) $>$ MWCNT (Figure 3). Following conclusions can be made from the observed result: (i) graphitic structure is necessary for electrochemical immobilization of sesamol as a redox confined system. (ii) Single-layered carbon nanomaterial provides better environment (surface orientation of the immobilized biomatrix and redox mediator) than the multiwalled carbon nanotube for electrochemical reaction modification. The exact interaction details are still not known. (iii) Oxygen-functionalized MWCNT and graphene oxide systems have a positive effect on the sesamol electrochemical oxidation reaction and immobilization. There might be a strong 
A.

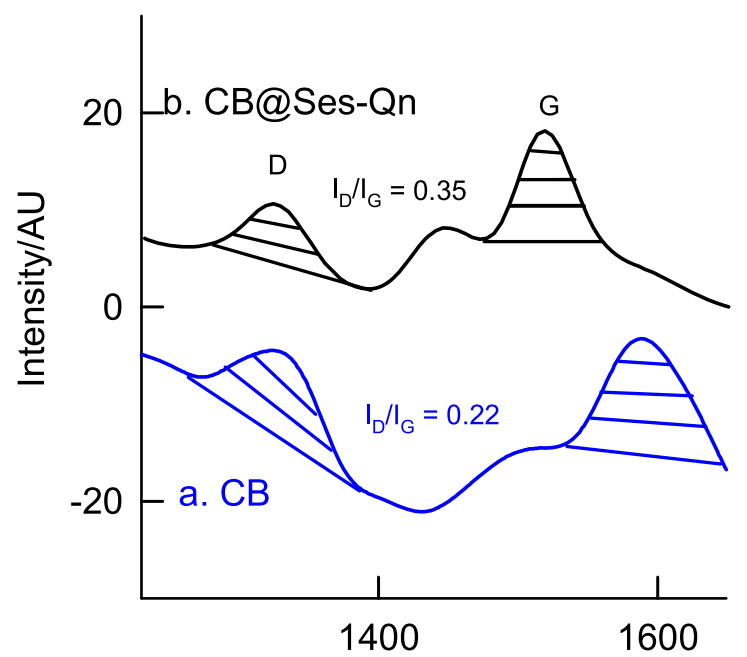

Raman Shift $/ \mathrm{cm}^{-1}$
B.

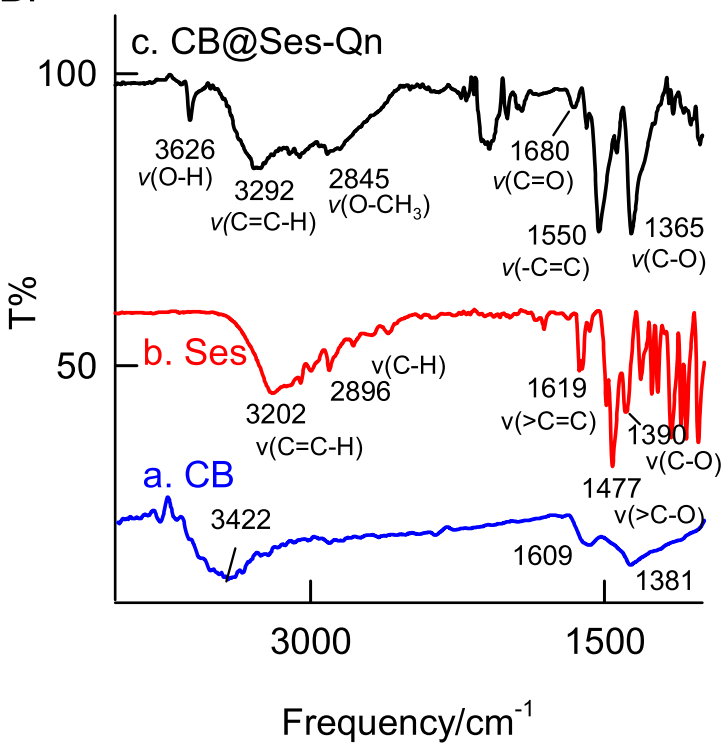

D.

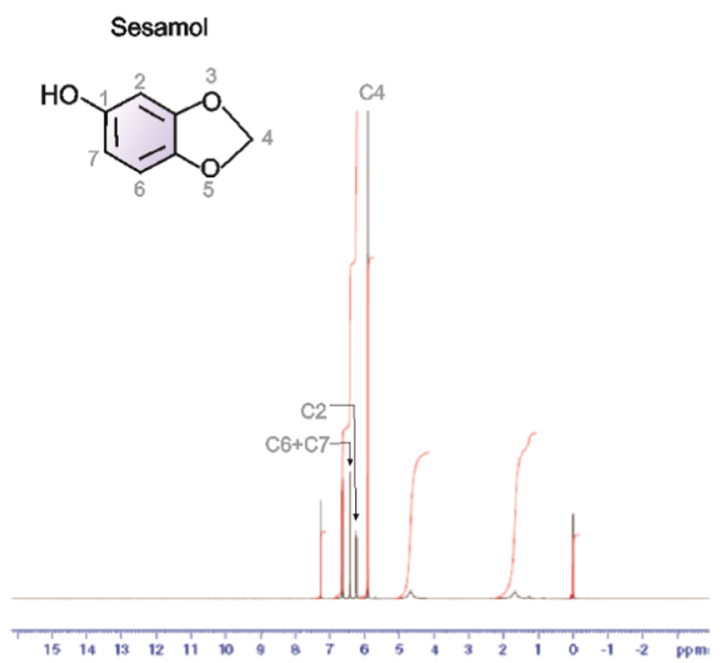

Figure 4. Raman (A) and FT-IR (B) responses of SPCE/CB@Ses-Qn and its control samples. (C, D) $\mathrm{CDCl}_{3}$-NMR of a methanolic extract of the GCE/CB@Ses-Qn and pure sesamol samples. Note that Ses-Qn = Ses-Oxid.

hydrogen bonding interaction between the hydroxyl/functional group of Ses-Oxid with $\mathrm{COOH}$ and $\mathrm{OH}$ functional groups of $\mathrm{CB}$, apart from the $\pi-\pi$ interaction on the modified electrode surface. Considering the highest current signal and surface excess values of sesamol loading, $\mathrm{CB}$ has been chosen as optimal for further experiment. At this stage, it is difficult to propose what type of sesamol-organic molecule is immobilized on $\mathrm{CB}$ and showed the redox feature. Several physicochemical and electrochemical characterizations were further carried out to confirm the product formed on the surface.

3.3. Physicochemical Characterization of CB@SesOxid. Figure 4A shows a comparative Raman spectroscopic response of CB and CB@Ses-Oxid that have been modified on screen-printed carbon electrodes. Specific Raman signals corresponding to $\mathrm{D}$ (due to the $\mathrm{sp}^{3}$ carbon) at $1351 \mathrm{~cm}^{-1}$ and $\mathrm{G}$ bands (due to $\mathrm{sp}^{2}$ carbon) at $1568 \mathrm{~cm}^{-1}$ were noticed. The calculated intensity ratios of the band, $I_{\mathrm{D}} / I_{\mathrm{G}}$, are 0.22 for $\mathrm{CB}$ and 0.35 for CB@Ses-Oxid. The increment of the $I_{\mathrm{D}} / I_{\mathrm{G}}$ ratio indicates the conversion of part of the $\mathrm{sp}^{2}$ carbon to $\mathrm{sp}^{3}$, which may be due to creation of oxygen functional groups on the modified electrode surface. In this context, generation of oxygen functional group on the sesamol-modified $\mathrm{CB}$ is the likely reason for the observation. FT-IR analysis is further used to assign the functional groups formed on the modified electrode surface. Figure 4B shows a typical comparative FTIR response of $\mathrm{CB}$, Ses, and $\mathrm{CB} @$ Ses-Oxid/KBr systems. For this experiment, the respective GCE-modified electrodes were carefully scratched out and mixed with $\mathrm{KBr}$ for the analysis. The blank sesamol compound showed specific IR signals at $3202 \mathrm{~cm}^{-1}$ ( $\mathrm{C}=\mathrm{CH}$; stretching), $2896 \mathrm{~cm}^{-1}$ (alkyl C-H stretching), $1619 \mathrm{~cm}^{-1}(\mathrm{C}=\mathrm{C}$; aromatic stretching), 1475 $\mathrm{cm}^{-1}$ (>C-O; symmetric stretch in dioxo-bridged carbon), and $1390 \mathrm{~cm}^{-1}\left(\nu \mathrm{CH}_{2}\right.$; stretching), whereas $\mathrm{CB} @$ Ses-Oxid showed signals at $3626 \mathrm{~cm}^{-1}(\nu \mathrm{O}-\mathrm{H}), 3292 \mathrm{~cm}^{-1}(\nu \mathrm{C}=\mathrm{CH}$; alkene stretching), $2845 \mathrm{~cm}^{-1}\left(\nu \mathrm{O}-\mathrm{CH}_{3}\right.$; methoxy group), $1680 \mathrm{~cm}^{-1}\left(\nu \mathrm{C}=\mathrm{O}\right.$; carbonyl), $1365 \mathrm{~cm}^{-1}(\nu \mathrm{C}-\mathrm{O}$; ether stretching), and $1550 \mathrm{~cm}^{-1}(\nu \mathrm{C}=\mathrm{C}-\mathrm{C}=\mathrm{O} ; \alpha-\beta$ unsaturated ketone). The peak corresponding to $2077 \mathrm{~cm}^{-1}$ is due to some 
Scheme 2. Possible Resonance Structures and Reaction Pathways of the Electrochemical Oxidation of Sesamol ${ }^{a}$

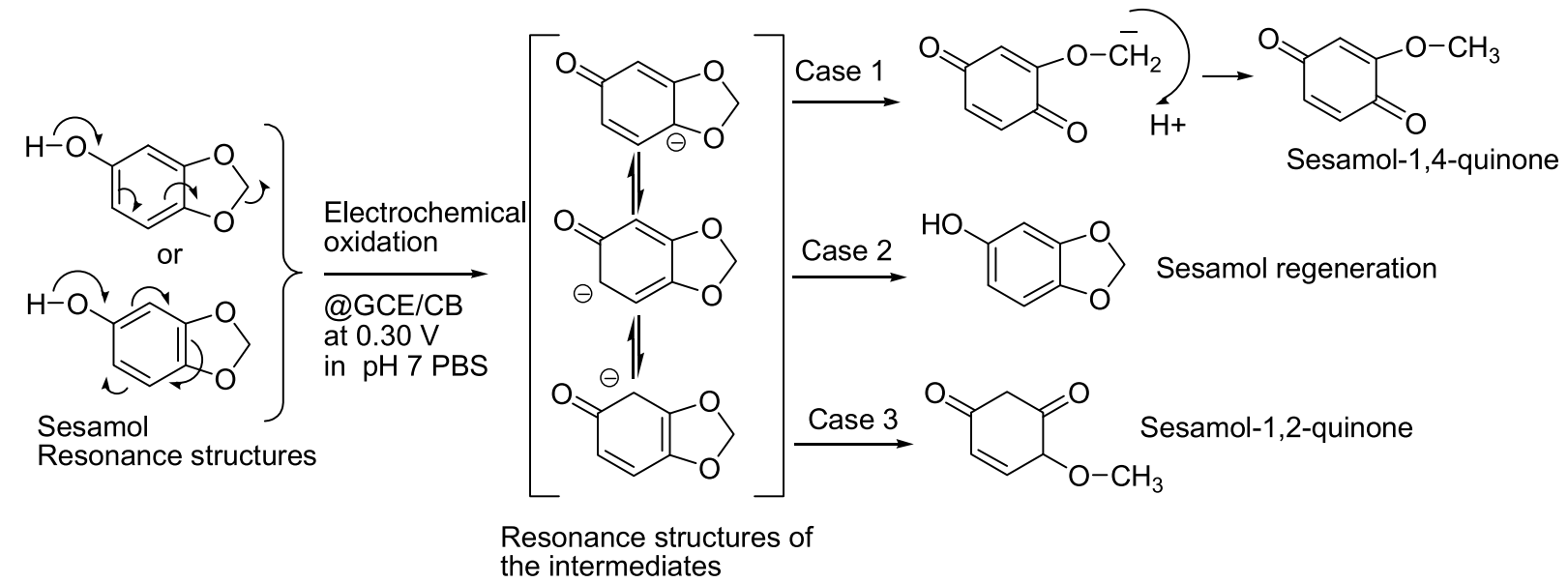

${ }^{a}$ As sesamol-1,4-quinone (sesamol-p-quinone; case 1), sesamol (regeneration; case 2), and sesamol-1,2-quinone (sesamol-o-quinone) on the GCE/ CB-modified electrode surface.

A.

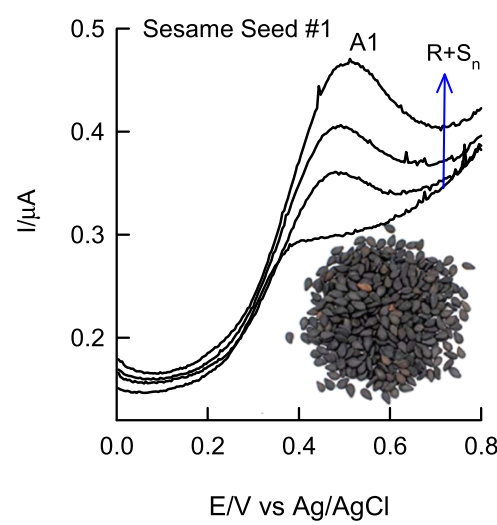

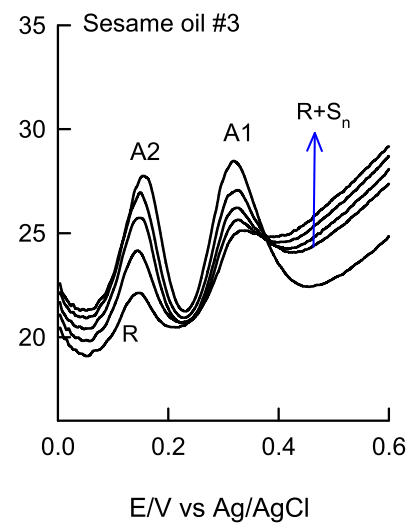

C.

D.

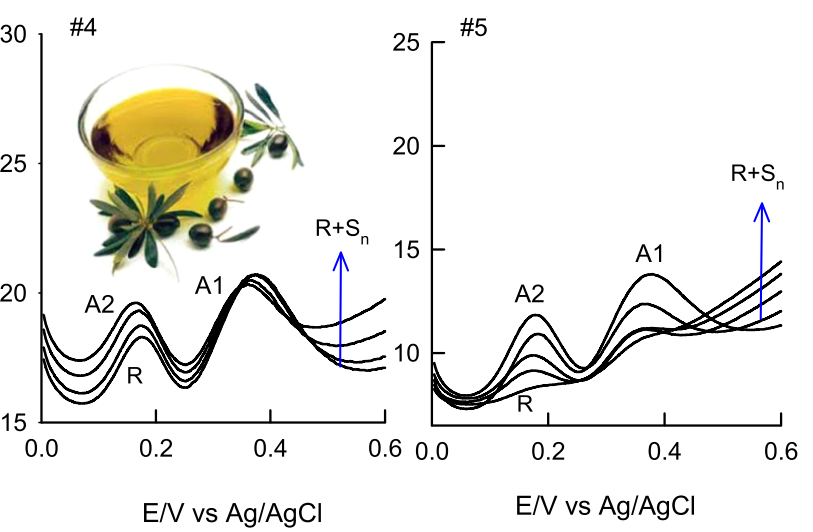

Figure 5. DPV of real sample analysis of sesame seed (\#1) and different sesame oil (\#3-\#5) varieties using the GC/CB-modified electrode by the standard addition approach. The first DPV run was taken uniformly for quantitative analysis.

impurity (adsorbed $\mathrm{CO}_{2}$ while measuring the IR signals). Note that new IR signals due to $\nu \mathrm{O}-\mathrm{H}$ and $\nu(\alpha-\beta$ unsaturated ketone) were observed specifically with the Ses-Oxid-modified electrode, which confirms the presence of a quinone motif on the modified electrode. ${ }^{63}$ To further confirm the structure, the modified electrode prepared by the bulk method, active-site extracted with methanol, filtered multiple times and dried sample was subjected to NMR analysis carefully as in Figure 4. Prior to the experiment, the sample was subjected to thin-layer chromatography, showing two spots (data not shown) for the positive response to the electrochemical oxidation reaction. As can been seen in Figure 4D, the proton NMR spectrum of the pure sesamol in $\mathrm{CDCl}_{3}$ showed characteristic signals $(\delta)$ at $6.78 \mathrm{ppm}$ (doublet, $1 \mathrm{H}$; aromatic hydrogen at $\mathrm{C} 7$ ), $6.45 \mathrm{ppm}$ (singlet, $1 \mathrm{H}$; aromatic hydrogen at $\mathrm{C} 2$ ), $6.35 \mathrm{ppm}$ (doublet, $1 \mathrm{H}$; aromatic hydrogen at $\mathrm{C} 6), 5.95 \mathrm{ppm}$ (singlet, $2 \mathrm{H}$; dioxo methylene bridge; C4), and $4.74 \mathrm{ppm}$ (broad singlet, $1 \mathrm{H}$ ). However, for the electrochemically oxidized sesamol, the signal was noticed at 3.8 (singlet, $3 \mathrm{H}$; methoxy; $\mathrm{C} 3$ ), 7.52 (singlet, $1 \mathrm{H}$; C2), 7.35-7.45 (merged, dd, $2 \mathrm{H} ; \mathrm{C5}$ and $\mathrm{C} 6$ ) corresponding to the dearomatized alkene protons (Figure 4C). The absence of the characteristic methylene bridge and aromatic proton but the appearance of a specific methoxy peak in the latter case (Figure $4 \mathrm{C}$ ) indicate the cleavage of $\mathrm{C}-\mathrm{O}$ bond, leading to the formation of a methoxy-substituted quinone product (Scheme 1A,B). On the basis of the collective physicochemical and spectrochemical characterization studies, it is revealed that the dioxo-bridge bond in sesamol is cleaved to respective phenol, which is then oxidized in situ as the respective quinone derivative on the underlying surface. Scheme 2 provides a plausible reaction pathway for the electrochemical oxidation of sesamol on the GCE/CBmodified electrode. It is visualized in case 1 that during the process of electron shifting, the sesamol intermediate molecule prefers to delocalize the electron and cleave the methylene dioxy bridge to form a sesamol-1,4-quinone derivative. As can be seen from case 2, sesamol is regenerated due to delocalization of electron within the aromatic system. As far as case 3 is concerned, a nonpreferred pathway, the formation of 1,3-quinone, is restricted due to resonance destabilization associated with 1,3-quinone. In fact, in our previous independent studies on electrochemical oxidation of phenol on the carbon nanotube-modified electrode showed selective formation of 1,4-diquinone as the final product. ${ }^{64}$ On the basis of the information, it can be confirmed that sesamol oxidation on the $\mathrm{GCE} / \mathrm{CB}$ surface resulted in the formation of the 
A.

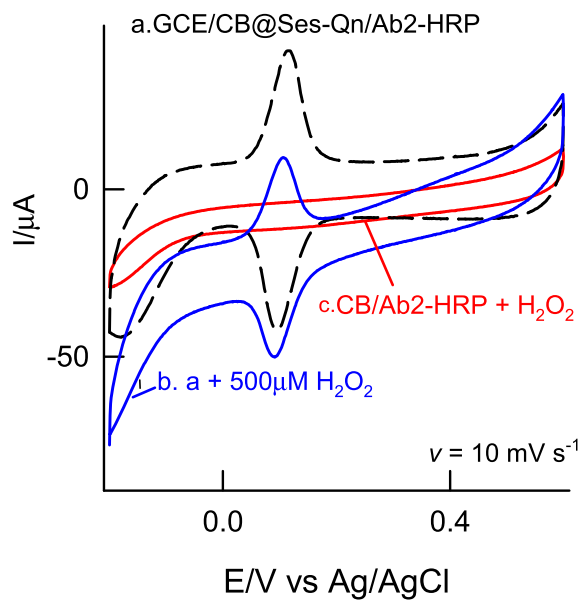

B.

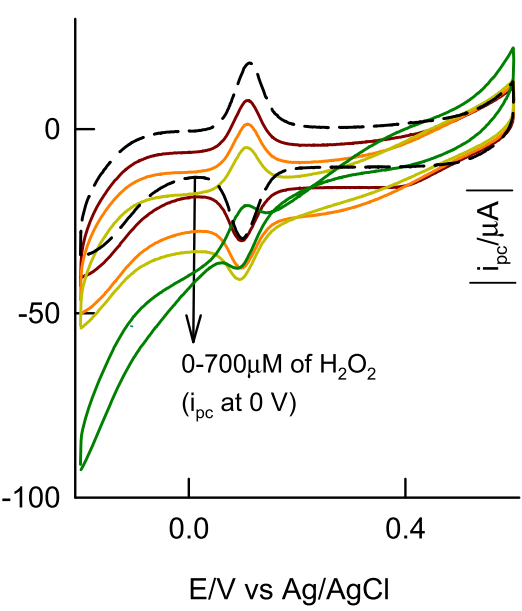

C.

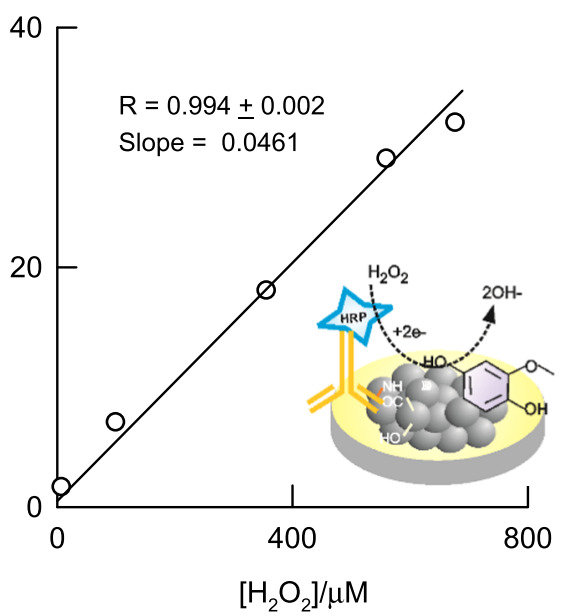

D.

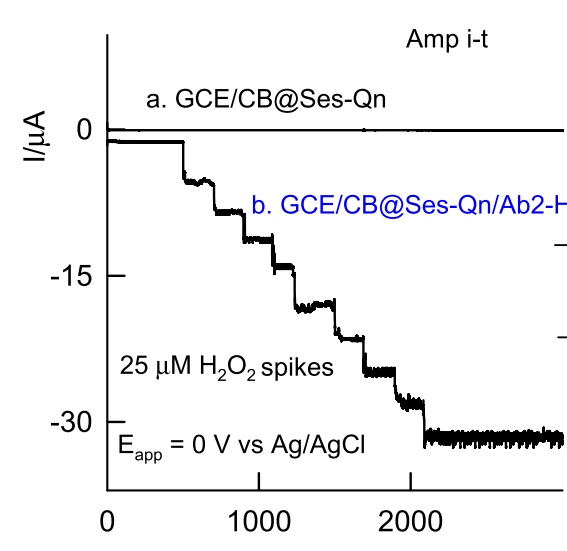

t/s
E.

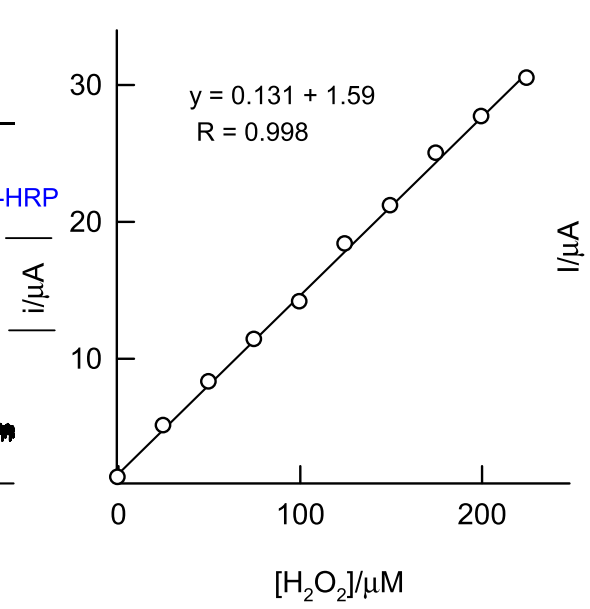

F.

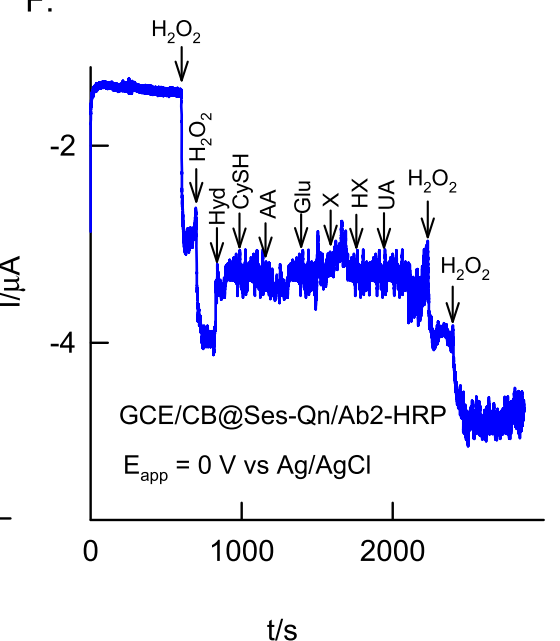

Figure 6. $\mathrm{CV}$ responses of the GCE/CB@Ses-Qn/Ab2-HRP modified electrode (A) without (a) and with $500 \mu \mathrm{M} \mathrm{H}_{2} \mathrm{O}_{2}(\mathrm{~b})$ and (B) with increasing concentration of $\mathrm{H}_{2} \mathrm{O}_{2}$ in $\mathrm{pH} 7 \mathrm{~PB}$ solution at $\mathrm{v}=10 \mathrm{mV} \mathrm{s}^{-1}$. (A) Curve c, shows a control CV of GCE/CB with $500 \mu \mathrm{M} \mathrm{H} \mathrm{O}_{2}$. (C) Plot of modulus $i_{\mathrm{pc}}$ vs $\left[\mathrm{H}_{2} \mathrm{O}_{2}\right]$. The inset cartoon is the illustration for the biosensor reaction. Amperometric $i-t$ responses of GCE/CB@Ses-Qn/ Ab2-HRP with 10 continuous spikes of $25 \mu \mathrm{M} \mathrm{H}_{2} \mathrm{O}_{2}$ (D) and spikes of $25 \mu \mathrm{M} \mathrm{H}_{2} \mathrm{O}_{2}$ and other interfering biochemicals such as hydrazine (Hyd), cysteine $(\mathrm{CysH})$, ascorbic acid (AA), glucose (Glu), xanthine (X), hypoxanthine ( $\mathrm{HX}$ ), and uric acid (UA) (F). (E) Plot of amperometric current signal vs $\left[\mathrm{H}_{2} \mathrm{O}_{2}\right]$.

sesamol-1,4-diquinone derivative as a surface-confined product. $^{64}$ From this point onward, the GCE/CB@Ses-Oxid is redesigned as GCE/CB@Ses-Qn, wherein Ses-Qn = sesamol1,4-quinone product.

3.4. Application 1: Sesamol Nutritive Content Estimation. Conventionally, high-performance liquid chromatography-coupled spectroscopic methods have been used for the estimation, ${ }^{65,66}$ which are time consuming ( $\sim 30 \mathrm{~min}$ per injection) and involve several offline preparation procedures. Herein, we introduce a differential pulse voltammetry-based quick quantification technique $(\sim 1 \mathrm{~min}$ per scan) for sesamol nutrient content estimation in the herbal products. For this analysis, the extracted real samples were directly spiked into $\mathrm{pH} 7 \mathrm{~PB}$ solution without $(\mathrm{R})$ and with standard concentrations of sesamol $(R+S n)$. Figure $5 A-D$ shows typical DPV responses of the sesame seed (\#1) and oil (\#3-\#5) samples tested by the DPV approach. The original spike of the test samples showed signals at A1 (\#1) and/or A2 (\#3-\#5) potentials with different current values. Depending on the nature of organic matter, different voltammetric responses (A1 or $\mathrm{A} 1$ and $\mathrm{A} 2$ ) were noticed. The DPV peak potential values noticed resemble with the respective values of the standard sesamol tested by the CV technique (Figure 1C). Upon spiking the standard alteration in A1 and/or A2, peak current signals were noticed. This observation confirms the appropriate quantification analysis of sesamol content in the real samples. Supporting Information Table S1 provides the analytical data of these assays. Note that the entire standard addition analysis can be done in $5 \pm 1 \mathrm{~min}$. On the basis of the linear equation and from the standard samples, contents of sesamol in the real systems were estimated as 352, 27.4, 213, and $278 \mathrm{mg}$ per $100 \mathrm{~g}$ in commercial seed (\#1) and oil (\#3\#5) samples, which are comparable to the values $34.2-613$ $\mathrm{mg} / 100 \mathrm{~g}$ sesamol content in various sesame seeds and other products determined by conventional techniques (Supporting Information, Table S1). ${ }^{38-40}$ On the basis of the standard spikes, calculated recovery values of the assays are $\sim 100 \%$, indicating the suitability of the present work for various real sample analyses. 
A.
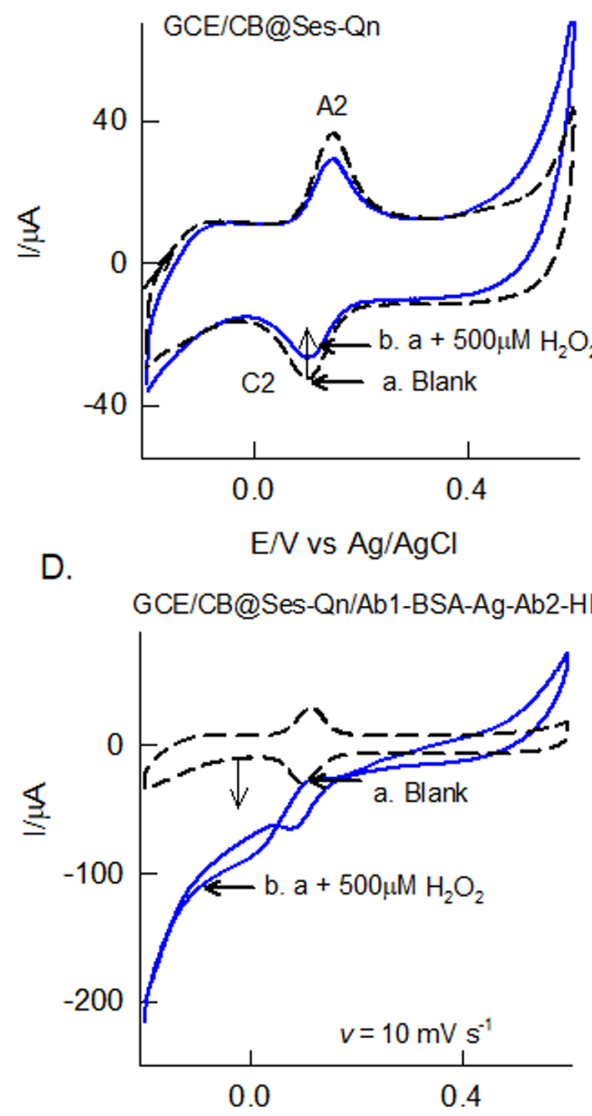

$\mathrm{E} / \mathrm{Vvs} \mathrm{Ag} / \mathrm{AgCl}$
B.

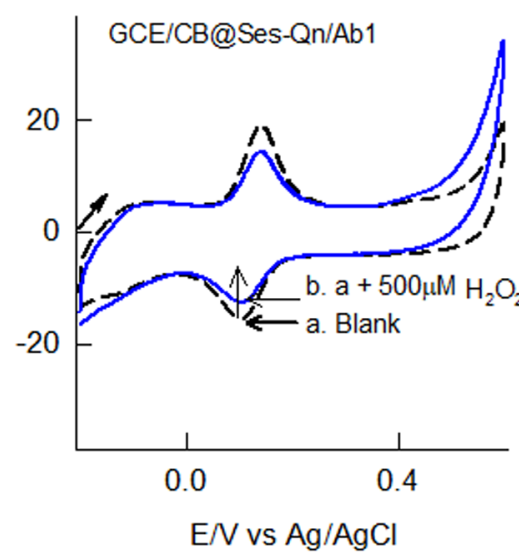

$\mathrm{E} / \mathrm{V}$ vs $\mathrm{Ag} / \mathrm{AgCl}$

E.

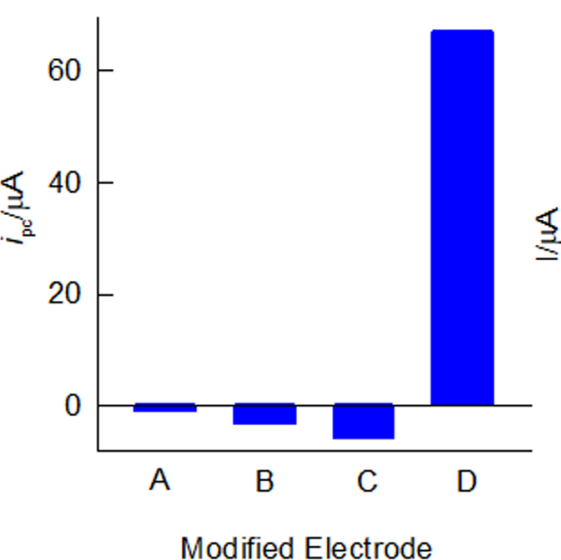

c.

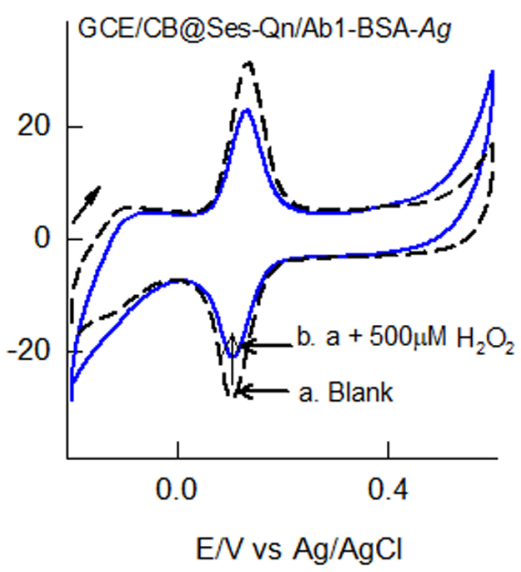

F.

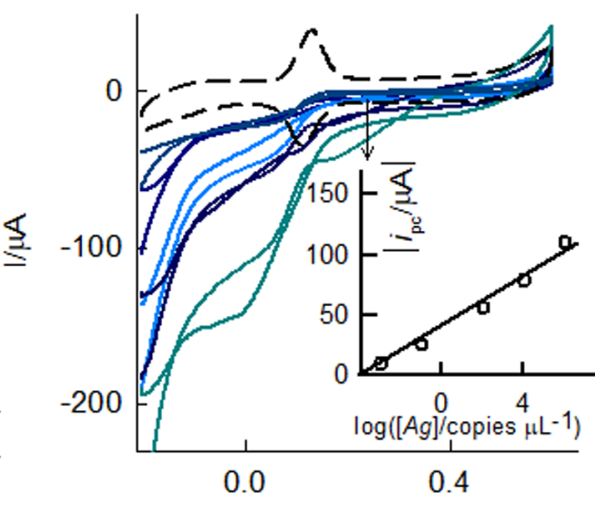

$\mathrm{E} / \mathrm{Vvs} \mathrm{Ag} / \mathrm{AgCl}$

Figure 7. CV responses of GCE/CB@Ses-Qn (A), GCE/CB@Ses-Qn/Ab1 (B), GCE/CB@Ses-Qn/Ab1-BSA-Ag (C), and GCE/CB@Ses-Qn/ Ab1-BSA-Ag-Ab2-HRP (D) without and with $500 \mu \mathrm{M} \mathrm{H}_{2} \mathrm{O}_{2}$ in $\mathrm{pH} 7 \mathrm{~PB}$ solution, $\nu=10 \mathrm{mV} \mathrm{s}^{-1}$. (E) Plot of modulus of $i_{\mathrm{pc}}$ vs various modified electrodes in the same order as above (current direction considered). The inset is the cartoon for the electrochemical immunosensor. (F) Effect of $\mathrm{Ag}$ (vp28) concentration $\left(1.31 \times 10^{-3}\right.$ to $1.31 \times 10^{7}$ copies $\left.\mu \mathrm{L}^{-1}\right)$ on the GCE/CB@Ses-Qn/Ab1-BSA-[Ag]-Ab2-HRP and its typical corresponding calibration graph as inset.

\subsection{Application 2: Bioelectrocatalytic Reduction and} Sensing of Hydrogen Peroxide. For this, Ab2-HRP was used as a bioenzyme system and immobilized on the GCE/ CB@Ses-Qn as GCE/CB@Ses-Qn/Ab2-HRP. The modified electrode was prepared by simple drop-casting of a dilute solution of Ab2-HRP, incubation at room temperature for $5 \pm$ $1 \mathrm{~min}$, washing with double-distilled water, and drying. It is expected that carboxylic acid functional groups of $\mathrm{CB}$ are involved in the coupling reaction with the amino functional group of the Ab2-HRP site as an amide linkage (Scheme 1). In our previous study on immobilization of polydopamine with carboxylic group-functionalized MWCNT, we observed a covalent link formation between them. ${ }^{67}$ In this work, we expect that a similar kind of covalent bonding is formed. Meanwhile, the mechanistic electron-transfer feature of the Ab2-HRP-modified electrode was examined. The typical $\mathrm{CV}$ response of the GCE/CB@Ses-Qn/Ab2-HRP (without $\mathrm{H}_{2} \mathrm{O}_{2}$ ) showed a redox peak similar to that in the case of the GCE/ $\mathrm{CB} @$ Ses, as shown in Figure 6. Comparative CV scan rate responses of GCE/CB@Ses-Qn and GCE/CB@Ses-Qn/Ab2HRP are displayed in Figure 2. The redox currents of the GCE/CB@Ses/Ab2-HRP are varying nearly linearly with the scan rate, indicating the adsorption-controlled electron-transfer feature of the modified electrode. Because the secondary antibody-integrated, sesamol-quinone-modified electrode is a nonideal system and contains fraction of electron-inactive protein, the $i_{\mathrm{pc}}$ vs $\nu$ plot does not follow straight line behavior. The calculated $\Gamma_{\text {Ses }}$ values are $58.37 \times 10^{-9}$ and $47.74 \times 10^{-10}$ mol cm${ }^{-2}$, respectively, for without and with Ab2-HRP. On the basis of $\Delta E_{\mathrm{p}}=73 \mathrm{mV}$ for GCE/CB@Ses-Ab2-HRP and referring to the Laviron equation, ${ }^{61}$ the calculated $1 / m, \alpha$, and $k_{\mathrm{s}}$ values are $2.2(m=0.33), 0.5$, and $1.28 \pm 0.5 \mathrm{~s}^{-1}$, respectively. When compared with the GCE/CB@Ses-Qn system, the enzyme-modified electrode showed about 5\% decrement in the kinetic parameter $\left(k_{\mathrm{s}}\right)$ value, which may be due to the electroinactive character of the Ab2-HRP. It is likely that the amino functional groups of Ab2-HRP interacted with carboxylic functional groups without any covalent linkers like EDC-NHS. Note that metal catalyst-assisted coupling of amine and carboxylic acid groups has been reported in the literature. $^{62,68}$ Plausibly, the trace metal impurities like $\mathrm{Ni}$ $(0.18 \mathrm{wt} \%)$ and $\mathrm{Fe}(0.42 \mathrm{wt} \%)^{69}$ in $\mathrm{CB}$ helps the amide linkage formation on the modified electrode surface. Figure $6 \mathrm{~A}$, curve $\mathrm{b}$, shows a typical $\mathrm{CV}$ response of the enzyme electrode with $500 \mu \mathrm{M} \mathrm{H}_{2} \mathrm{O}_{2}$. As can be seen, specific increment in the reduction current signal where the $\mathrm{A} 2 / \mathrm{C} 2$ peak exists was noticed. As a control experiment, GCE/CB@Ses-Qn without any Ab2-HRP was subjected to $\mathrm{H}_{2} \mathrm{O}_{2}$, as shown in curve $\mathrm{c}$ in 
A.

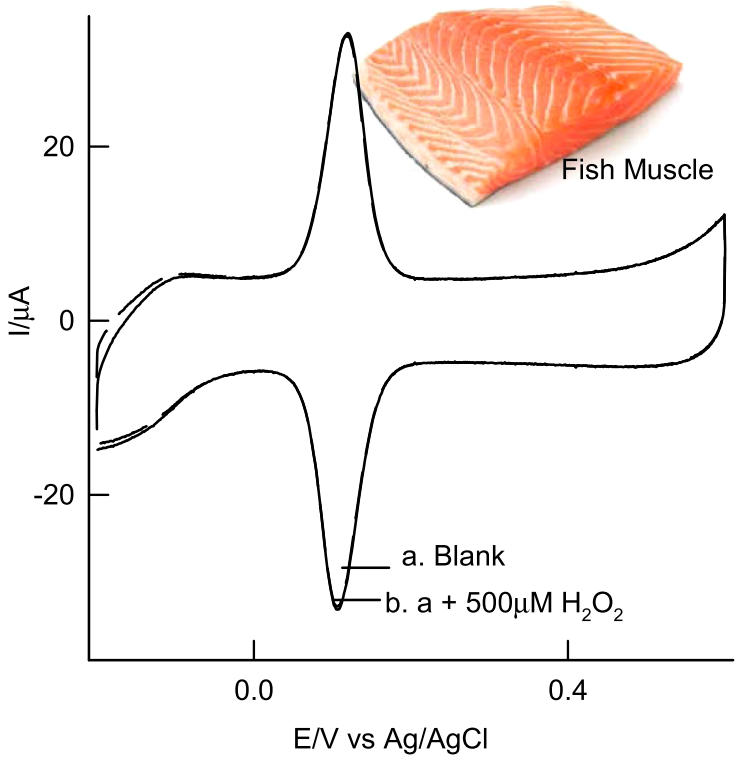

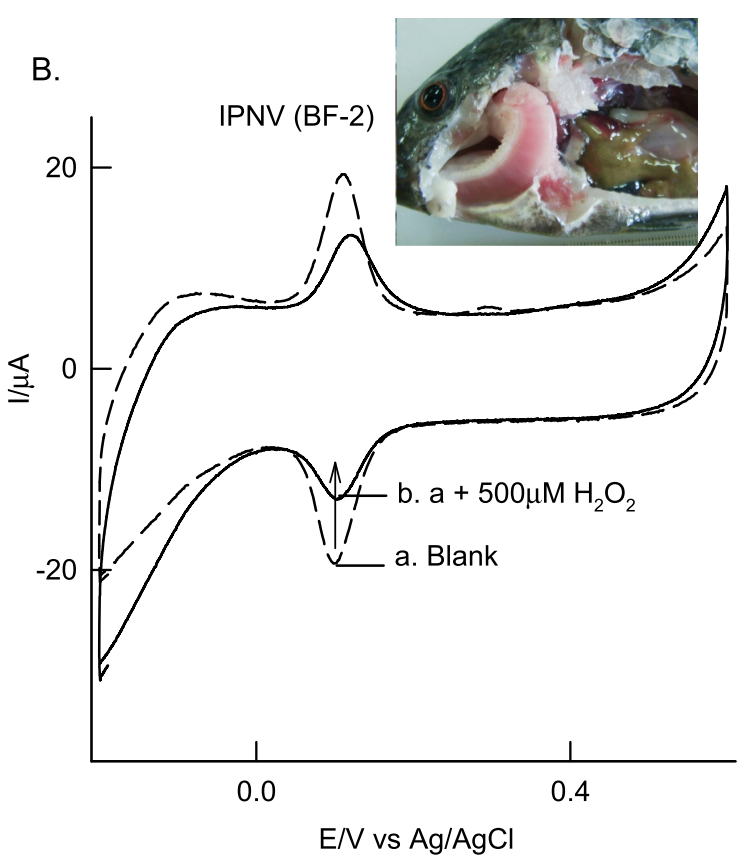

Figure 8. Specificity experiment of CV responses of GCE/CB@Ses-Qn/Ab1-fish muscle-BSA-Ab2-HRP (A) and GCE/CB@Ses-Qn/Ab1$\operatorname{IPNV}(\mathrm{BF}-2)$-BSA-Ab2-HRP (B) in $\mathrm{pH} 7 \mathrm{~PB}$ solution. Scan rate $=10 \mathrm{mV} \mathrm{s}^{-1}$.

Figure 7A. There is no sign for the $\mathrm{H}_{2} \mathrm{O}_{2}$ reduction current with the above case, ensuring that the electrochemical response observed is not due to the sesamol and carbon matrix. This information confirms the bioelectrocatalytic reduction of $\mathrm{H}_{2} \mathrm{O}_{2}$ coassisted (transducer) by the sesamol-Qn redox system in this work. The possible mechanism for the bioelectrocatalytic reaction is sketched in Scheme 1. Further experiments on the effect of concentration showed a linear increase in the current values. Currents measured at $0 \mathrm{~V}$ vs $\mathrm{Ag} / \mathrm{AgCl}$ are uniformly taken for the quantitative analysis. The constructed calibration plot was linear in a window of $0-700 \mu \mathrm{M}$ with current sensitivity and regression coefficient values 0.0461 and 0.994 $\mu \mathrm{A} \mu \mathrm{M}^{-1}$, respectively. Furthermore, the amperometric $i-t$ technique was adopted for the bioelectrochemical sensing of $\mathrm{H}_{2} \mathrm{O}_{2}$. Figure 6C-E shows the comparative responses of GCE/CB@Ses-Qn (control) and GCE/CB@Ses-Qn/Ab2$\mathrm{HRP}$ for the continuous sensing of $25 \mu \mathrm{M} \mathrm{H}_{2} \mathrm{O}_{2}$ spiked $\mathrm{pH}$ $7 \mathrm{~PB}$ solution. A marked and regular increase in the current signal upon the $\mathrm{H}_{2} \mathrm{O}_{2}$ spike was noticed with the optimal electrode, whereas the control system failed to display any response under similar conditions. Thus, the study aids the idea of bioelectrocatalytic reduction by the optimal electrode. Figure $6 \mathrm{D}$ describes the calibration plot using the amperometric $i-t$ studies for the range $0-300 \mu \mathrm{M}$ of $\mathrm{H}_{2} \mathrm{O}_{2}$, and the resulting current sensitivity and regression coefficient values are 0.131 and $0.9998 \mu \mathrm{A} \mu \mathrm{M}^{-1}$, respectively. The relative standard deviation (RSD) for 10 spikes is $2.6 \%$. The calculated detection limit is $990 \mathrm{nM}$. The detection limit value was better than the values reported with the following biosensors: HRP/ thionine $/ \mathrm{TiO}_{2}$ nanotubes $(1.1 \mu \mathrm{M}),{ }^{70}$ porous Au-nano/ $\left.\mathrm{CaCO}_{3} / \mathrm{HPR}(1 \mu \mathrm{M})\right)^{71}$ and $\mathrm{Au} /$ sol-gel $\mathrm{SiO}_{2} / \mathrm{HPR}$ (3 $\mu \mathrm{M}){ }^{72}$ The biosensor found to be highly selective current signal to $\mathrm{H}_{2} \mathrm{O}_{2}$ without any interference from common biochemicals such as cysteine $(\mathrm{CysH})$, ascorbic acid (AA), glucose $(\mathrm{Glu})$, xanthine $(\mathrm{X})$, hypoxanthine $(\mathrm{HX})$, uric acid (UA), and hydrazine (Figure 6E).
3.6. Application-3: Electrochemical Immunosensor for WSSV. The fabrication of the electrochemical immunosensor has been shown in Scheme 1D-F. Sequential modification of Ab1, BSA, Ag, and Ab2-HRP and the corresponding $\mathrm{CV}$ responses without and with $500 \mu \mathrm{M}$ $\mathrm{H}_{2} \mathrm{O}_{2}$ are displayed in Figure $7 \mathrm{~A}-\mathrm{D}$. As can be seen, the controls, GCE/CB@Ses-Qn, GCE/CB@Ses-Qn/Ab1, and GCE/CB@Ses-Qn/Ab1-BSA-Ag were failed to show any bioelectrocatalytic current signal (negative response was obtained), indicating the absence of any false positive response noticed in this work (Figure $7 \mathrm{E}$ ). CV of the electrochemical immunosensor, GCE/CB@Ses-Qn/Ab1-BSA-Ag-Ab2-HRP, showed a sensitive bioelectrocatalytic response to $\mathrm{H}_{2} \mathrm{O}_{2}$. Upon increasing the $\mathrm{Ag}$ concentration $\left(1.31 \times 10^{-3}\right.$ to 1.31 $\times 10^{7}$ copies $\left.\mu \mathrm{L}^{-1}\right)$ in the electrochemical immunosensor construction, a systematic increase in the bioelectrocatalytic $\mathrm{H}_{2} \mathrm{O}_{2}$ reduction current signal was noticed, indicating the sensitive quantification analysis of the WSSV by the sesamolbased electrochemical platform. As an important control experiment, proteins obtained from fish muscle and IPNV were also modified on the electrode along with the other sequencers (Figure 8 ) but failed to show any $\mathrm{H}_{2} \mathrm{O}_{2}$ bioelectrocatalytic response evidencing the high specificity of the present electrochemical sensor for the WSSV analysis. Overall, the Ses-Qn based electrochemical platform is demonstrated to be the first, fair, elegant, novel and efficient for the various bioelectrochemical applications.

\section{CONCLUSIONS}

Electrochemical oxidation of electroinactive sesamol to a highly redox-active sesamol-quinone surface-confined system was achieved on a carbon nanoblack-modified glassy carbon electrode surface in $\mathrm{pH} 7 \mathrm{~PB}$ solution. The modified electrode showed a well-defined redox peak at a standard electrode potential $0.1 \mathrm{~V}$ vs $\mathrm{Ag} / \mathrm{AgCl}$ corresponding to the quinone/ hydroquinone redox-active site of the modified electrode (i.e., sesamol-quinone). Physicochemical characterization of the 
modified electrode and its extract by Raman and IR spectroscopic techniques and NMR study revealed that the dioxo bond of the sesamol was cleaved after the electrochemical preparation procedure, resulting in the sesamolquinone product on the working electrode surface. The new electrochemical platform introduced in this work was extended to (i) quantification of sesamol nutrient content in certain herbs (seed and oil), wherein the herbal extract was directly spiked into $\mathrm{pH} 7 \mathrm{~PB}$ solution and the oxidation reaction was analyzed for the quantification assays; (ii) bioelectrocatalytic reduction of $\mathrm{H}_{2} \mathrm{O}_{2}$ utilizing the sesamol-quinone as an ecofriendly transducer, for a sensitive and selective amperometric signal for $\mathrm{H}_{2} \mathrm{O}_{2}$ with current sensitivity and detection limit values $0.131 \mu \mathrm{A} \mu \mathrm{M}^{-1}$ and $990 \mathrm{nM}$, respectively, without any interference from common biochemicals such as $\mathrm{H}_{2} \mathrm{O}_{2}$, cysteine, ascorbic acid, glucose, xanthine, hypoxanthine, uric acid, and hydrazine; (iii) electrochemical immunosensing of WSSV, wherein sequential modification of primary antibody, BSA, antigen, and secondary antibody on GCE/CB@Ses-Qn was performed and tested with $\mathrm{H}_{2} \mathrm{O}_{2}$. The electrochemical immunosensor showed a highly selective and specific current signal to WSSV in a concentration window of $1.31 \times 10^{-3}$ to $1.31 \times 10^{7}$ copies $\mu \mathrm{L}^{-1}$ and copied $0.92 \mu \mathrm{A}$ copy $^{-1}$. Because the new electrochemical platform introduced was based on a nontoxic, nonhazardous, and herbal product, the approach can be used for a variety of electroanalytical and bioelectroanalytical applications in a sustained manner. In summary, following are the advantages of using sesamol as redox mediators: (i) the sesamol derivative (Ses-Qn) used in this work is generated from a renewable source, i.e., a phytochemical, a naturally occurring plant product. (ii) It is of low cost and quite easily available in the market. Hence, no additional effort is needed to synthesize the molecule. (iii) It is a part of a green chemistry approach, with no detrimental impact on the environment, unlike common electron mediators such as thionine, methylene blue, etc. that are a part of organic dyes and can be harmful to the flora and fauna. (iv) This approach involves a step targeting sustainable chemistry. Following is the limitation for this technique: (i) the formation of Ses-Qn is "in situ", i.e., the immobilization of the derivative involves the electrochemical preparation step before proceeding for the application work.

\section{ASSOCIATED CONTENT}

\section{S Supporting Information}

The Supporting Information is available free of charge on the ACS Publications website at DOI: 10.1021/acsomega.8b01296.

Table S1, sesamol sample analyses for various sesame products (seeds and oils) employing GCE/CB as a electrochemical detector (PDF)

\section{AUTHOR INFORMATION}

\section{Corresponding Authors}

*E-mail: Desikan.Rajagopal@ucf.edu, rajagopal.desikan@vit. ac.in. Phone: +1-407 590 3978, +91-416-2202330 (D.R.).

*E-mail: askumarchem@yahoo.com, askumar@vit.ac.in. Phone: +91-416-2202754 (A.S.K.).

\section{ORCID}

Sheng-Tung Huang: 0000-0003-0214-6436

Annamalai Senthil Kumar: 0000-0001-8800-4038

\section{Funding}

This work was funded by the Department of Science and Technology, Science Engineering Research Board and Department of Biotechnology, India.

\section{Notes}

The authors declare no competing financial interest.

\section{ACKNOWLEDGMENTS}

The authors acknowledge the Department of Science and Technology, Science and Engineering Research Board (DSTSERB-EMR/2016/002818) Scheme. Part of this work is supported by the Department of Biotechnology (BT/ PR17200/AAQ/3/768/2016). A.S.K. acknowledges the National Taipei University of Technology for the support of the distinguished visiting professor program.

\section{REFERENCES}

(1) Nurmi, J. T.; Tratnyek, P. G. Electrochemistry of Natural Organic Matter. ACS Symp. Ser. 2011, 129-151.

(2) Hofmann, J. D.; Pfanschilling, F. L.; Krawczyk, N.; Geigle, P.; Hong, L.; Schmalisch, S.; Wegner, H. A.; Mollenhauer, D.; Janek, J.; Schröder, D. Quest for Organic Active Materials for Redox Flow Batteries: 2,3-Diaza-anthraquinones and Their Electrochemical Properties. Chem. Mater. 2018, 30, 762-774.

(3) Zhang, Y.; Chu, M.; Yang, L.; Tan, Y.; Deng, W.; Ma, M.; Su, X.; Xie, Q. Three-Dimensional Graphene Networks as a New Substrate for Immobilization of Laccase and Dopamine and Its Application in Glucose $/ \mathrm{O}_{2}$ Biofuel Cell. ACS Appl. Mater. Interfaces 2014, 6, 1280812814.

(4) Vikesland, P. J.; Ozekin, K.; Valentine, R. L. Effect of Natural Organic Matter on Monochloramine Decomposition: Pathway Elucidation through the Use of Mass and Redox Balances. Environ. Sci. Technol. 1998, 32, 1409-1416.

(5) Sarauli, D.; Peters, K.; Xu, C.; Schulz, B.; Fattakhova-Rohlfing, D.; Lisdat, F. 3D-Electrode Architectures for Enhanced Direct Bioelectrocatalysis of Pyrroloquinoline Quinone-Dependent Glucose Dehydrogenase. ACS Appl. Mater. Interfaces 2014, 6, 17887-17893.

(6) Carretero-González, J.; Martınez, C. E.; Armand, M. Highly Water-Soluble Three-Redox State Organic Eyes as Bifunctional Analytes. Energy Environ. Sci. 2016, 9, 3521-3530.

(7) Gayathri, P.; Kumar, A. S.; Kamaraj, S. An Unusual Electrochemical Reductive Cleavage of Azodye into Highly Redox Active Copolymeric Aniline Derivatives on a MWCNT Modified Electrode Surface in Neutral $\mathrm{pH}$ and Its Electro-analytical Features. J. Phys. Chem. C 2015, 119, 7791-7801.

(8) Zasonská, B.; Cadkova, M.; Kovarova, A.; Bilkova, Z.; Korecka, L.; Horak, D. Thionine-modified Poly(glycidyl methacrylate) Nanospheres as Labels of Antibodies for Biosensing Applications. ACS Appl. Mater. Interfaces 2015, 7, 24926-24931.

(9) Yu, D.; Wang, H.; Yang, J.; Niu, Z.; Lu, H.; Yang, Y.; Cheng, L.; Guo, L. Dye Wastewater Cleanup by Graphene Composite Paper for Tailorable Supercapacitors. ACS Appl. Mater. Interfaces 2017, 9, 21298-21306.

(10) Amreen, K.; Kumar, A. S. Highly Redox Active HematinFunctionalized Carbon Mesoporous Nanomaterial for ElectroCatalytic Reduction Applications in Neutral Media. ACS Appl. Nano Mater. 2018, 2272-2283.

(11) Zhang, Y.; Schulz, M.; Wächtler, M.; Karnahl, M.; Dietzek, B. Heteroleptic Diimine-Diphosphine $\mathrm{Cu}(\mathrm{I})$ Complexes as an Alternative Towards Noble-Metal Based Photosensitizers: Design Strategies, Photophysical Properties and Perspective Applications; Review. Coord. Chem. Rev. 2018, 356, 127-146.

(12) Kumar, A. S.; Tanase, T.; Iida, M. In Situ Nanostructure Formation of ( $\mu$-Hydroxo $)$ bis $(\mu$-carboxylato) Diruthenium Units in Nafion Membrane and Its Utilization for Selective Reduction of Nitrosonium Ion in Aqueous Medium. Langmuir 2007, 23, 391-394. 
(13) Lin, Y.; Zhou, Q.; Tang, D.; Niessner, R.; Knoop, D. Signal-OnPhotoelectrochemical Immunoassay for Aflatoxin B1 Based Immunoassay for Enzymatic Product-Etching $\mathrm{MnO}_{2}$ Nanosheets for Dissociation of Carbon Dots. Anal. Chem. 2017, 89, 5637-5645.

(14) Qiu, Z.; Shu, J.; Tang, D. Near-Infrared-to-Ultraviolet LightMediated Photoelectrochemical Aptasensing Platform for Cancer Biomarker Based on Core-Shell $\mathrm{NaYF}_{4}: \mathrm{Yb}, \mathrm{Tm} @ \mathrm{TiO}_{2}$ Upconversion Microrods. Anal. Chem. 2018, 90, 1021-1029.

(15) Lv, S.; Zhang, K.; Zeng, Y.; Tang, D. Double PhotosystemsBased 'Z-Scheme' for Photoelectrochemical Sensing Mode for Ultrasensitive Detection of Disease Biomarker Accompanying 3D DNA Walker. Anal. Chem. 2018, 90, 7086-7107.

(16) Zen, J.-M.; Tsai, D.-M.; Kumar, A. S.; Dharuman, V. Amperometric Determination of Ascorbic Acid at a FerricyanideDoped Tosflex-Modified Electrode. Electrochem. Commun. 2000, 2, 782-785.

(17) Ertl, P.; Robello, E.; Battaglini, F.; Mikkelsen, S. R. Rapid Antibiotic Susceptibility Testing via Electrochemical Measurement of Ferricyanide Reduction by Escherichia coli and Clostridium sporogenes. Anal. Chem. 2000, 72, 4957-4964.

(18) Boon, E. M.; Barton, J. K.; Bhagat, V.; Nersissian, M.; Wang, W.; Hill, M. G. Reduction of Ferricyanide by Methylene Blue at a DNA-Modified Rotating-Disk Electrode. Langmuir 2003, 19, 92559259.

(19) Lepage, P. H.; Peytavi, R.; Bergeron, M. G.; Leclerc, M. Amplification Strategy Using Aggregates of Ferrocene-Containing Cationic Polythiophene for Sensitive and Specific Electrochemical Detection of DNA. Anal. Chem. 2011, 83, 8086-8092.

(20) Manibalan, K.; Mani, P.; Chang, P.-C.; Huang, C.-H.; Huang, S. T.; Marchlewicz, C.; Neethirajan, S. Electrochemical Latent Redox Ratiometric Probes for Real-Time Tracking and Quantification of Endogenous Hydrogen Sulfide Production in Living Cells. Biosens. Bioelectron. 2017, 96, 233-238.

(21) Tsai, Y.-C.; Coles, B. A.; Compton, R. G.; Marken, F. Microwave Activation of Electrochemical Processes: Enhanced Electrodehalogenation in Organic Solvent Media. J. Am. Chem. Soc. 2002, 124, 9784-9788.

(22) Gad, S. C. Encyclopedia of Toxicology; Elsevier Inc, 2005; Vol. 2, pp 555-557.

(23) Polyakov, N.; Leshina, T.; Fedenok, L.; Slepneva, I.; Kirilyuk, I.; Furso, J.; Olchawa, M.; Sarna, T.; Elas, M.; Bilkis, I.; Weiner, L. Redox-Active Quinone Chelators: Properties, Mechanisms of Action, Cell Delivery, and Cell Toxicity. Antioxid. Redox Signaling 2018, 28, 1394-1403.

(24) Liang, C.; Zhang, X.; Wang, W.; Song, Y.; Jia, X. A Subchronic Oral Toxicity Study on Pyrroloquinoline Quinone (PQQ) Disodium Salt in Rats. Food Chem. Toxicol. 2015, 75, 146-150.

(25) Walpen, N.; Getzinger, G. J.; Schroth, M. H.; Sander, M. Electron-Donating Phenolic and Electron-Accepting Quinone Moieties in Peat Dissolved Organic Matter: Quantities and Redox Transformations in the Context of Peat Biogeochemistry. Environ. Sci. Technol. 2018, 52, 5236-5245.

(26) Khan, S.; Malik, A. Toxicity Evaluation of Textile Effluents and Role of Native Soil Bacterium in Biodegradation of a Textile Dye. Environ. Sci. Pollut. Res. Int. 2018, 25, 4446-4458.

(27) Shu, J.; Tang, D. Current Advances in Quantum-Dots-Based Photoelectrochemical Immunoassays. Chem. - Asian J. 2017, 12, $2780-2789$.

(28) do Céu Silva, M.; Gaspar, J.; Duarte Silva, I.; Leão, D.; Rueff, J. Mechanisms of Induction of Chromosomal Aberrations by Hydroquinone in V79 cells. Mutagenesis 2003, 18, 491-496.

(29) McGregor, D. Hydroquinone: An Evaluation of the Human Risks from its Carcinogenic and Mutagenic Properties. Crit. Rev. Toxicol. 2007, 37, 887-914.

(30) Peters, M. M. C. G.; Rivera, M. I.; Jones, T. W.; Monks, T. J.; Lau, S. S. Glutathione Conjugates of Tert-Butyl-Hydroquinone, a Metabolite of the Urinary Tract Tumor Promoter 3-Tert-ButylHydroxyanisole, are Toxic to Kidney and Bladder. Cancer Res. 1996, $56,1006-1011$.
(31) Pulce, C.; Descotes, J. Lethal Acute Poisoning with Potassium Ferrocyanide. Am. J. Emerg. Med. 2010, 28, 642.e3-642.e5.

(32) Domingo, P. L.; Garcia, B.; Leal, J. M. Acid-Base Behaviour of the Ferricyanide ion in Perchloric Acid Media. Spectrophotometric and Kinetic Study. Can. J. Chem. 1990, 68, 228-235.

(33) Yeary, R. A. Chronic Toxicity of Dicyclopentadienyl iron (Ferrocene) in Dogs. Toxicol. Appl. Pharmacol. 1969, 15, 666-676.

(34) Amreen, K.; Shukla, V. K.; Shukla, S.; Desikan, R.; Kumar, A. S. Redox Behaviour and Surface-Confinement of Electro Active Species of Ginger Extract on Graphitized Mesoporous Carbon Surface and its Copper Complex for $\mathrm{H}_{2} \mathrm{O}_{2}$ Sensing. Nanostruct. Nanoobjects 2017, 11, $56-64$.

(35) Dinesh, B.; Shalini Devi, K. S.; Kumar, A. S. CurcuminQuinone Immobilised Carbon Black Modified Electrode Prepared by In-Situ Electrochemical Oxidation of Curcumin-Phytonutrient for Mediated Oxidation and Flow Injection Analysis of Sulphide. J. Electroanal. Chem. 2017, 804, 116-127.

(36) Barathi, P.; Kumar, A. S. Quercetin Tethered PristineMultiwalled Carbon Nanotube Modified Glassy Carbon Electrode as an Efficient Electrochemical Detector for Flow Injection Analysis of Hydrazine in Cigarette Tobacco Samples. Electrochim. Acta 2014, 135, $1-10$.

(37) Kumar, A. S.; Shanmugam, R.; Vishnu, N.; Pillai, K. C.; Kamaraj, S. Electrochemical Immobilization of Ellagic acid Phytochemical on MWCNT Modified Glassy Carbon Electrode Surface and its Efficient Hydrazine Electrocatalytic Activity in Neutral pH. J. Electroanal. Chem. 2016, 782, 215-224.

(38) Beroza, M.; Kinman, M. L. Sesamin, Sesamolin, and Sesamol Content of the Oil of Sesame Seed as Affected by Strain, Location Grown, Ageing, and Frost Damage. J. Am. Oil Chem. Soc. 1955, 32, 348-350.

(39) Sadeghi, N.; Oveisi, M. R.; Hajimahmoodi, M.; Jannat, B.; Mazaheri, M.; Mansouri, S. The Contents of Sesamol in Iranian Sesame Seeds. Iran. J. Pharm. Res. 2009, 8, 101-105.

(40) Ambrose, A. M.; Cox, A. J., Jr.; DeEds, F. Antioxidant Toxicity, Toxicological Studies on Sesamol. J. Agric. Food Chem. 1958, 6, 600604

(41) Galano, A.; Alvarez-Idaboy, J. R.; Francisco-Marquez, M. Physicochemical Insights on the Free Radical Scavenging Activity of Sesamol: Importance of the Acid/Base Equilibrium. J. Phys. Chem. B 2011, 115, 13101-13109.

(42) Ansari, M. A.; Fatima, Z.; Hameed, S. Mechanistic Insights into the Mode of Action of Anticandidal Sesamol. Microb. Pathog. 2016, 98, 140-148.

(43) Kuhad, A.; Sachdeva, A. K.; Chopra, K. Attenuation of Renoinflammatory Cascade in Experimental Model of Diabetic Nephropathy by Sesamol. J. Agric. Food Chem. 2009, 57, 6123-6128.

(44) Geetha, T.; Deol, P. K.; Kaur, I. P. Role of Sesamol-Loaded Floating Beads in Gastric Cancers: A Pharmacokinetic and Biochemical Evidence. J. Microencapsulation 2015, 32, 478-487.

(45) Geetha, T.; Kapila, M.; Prakash, O.; Deol, P. K.; Kakkar, V.; Kaur, I. P. Sesamol-Loaded Solid Lipid Nanoparticles for Treatment of Skin Cancer. J. Drug Targeting 2015, 23, 159-169.

(46) Vennila, L.; Pugalendi, K. V. Protective Effect of Sesamol Against Myocardial Infarction Caused by Isoproterenol in Wistar Rats. Redox Rep. 2010, 15, 36-42.

(47) Brito, R. E.; Mellado, J. M. R.; Maldonado, P.; Montoya, M. R.; Palma, A.; Morales, E. Elucidation of the Electrochemical Oxidation Mechanism of the Antioxidant Sesamol on a Glassy Carbon Electrode. J. Electrochem. Soc. 2014, 161, G27-G32.

(48) Chevion, S.; Roberts, M. A.; Chevion, M. The Use of Cyclic Voltammetry for the Evaluation of Antioxidant Activity. Free Radical Biol. Med. 2000, 28, 860-870.

(49) Abraham, I.; Joshi, R.; Pardasani, P.; Pardasani, R. T. Recent Advances in 1,4-Benzoquinone Chemistry. J. Braz. Chem. Soc. 2011, $22,385-421$.

(50) Natarajan, A.; Devi, K. S.; Raja, S.; Kumar, A. S. An Elegant Analysis of White Spot Syndrome Virus Using a Graphene Oxide/ 
Methylene Blue based Electrochemical Immunosensor Platform. Sci. Rep. 2017, 7, No. 46169.

(51) Verma, S.; Singh, A.; Shukla, A.; Kaswan, J.; Arora, K.; RamirezVick, J.; Singh, P.; Singh, S. P. Anti-IL8/AuNPs-rGO/ITO as an Immunosensing Platform for Noninvasive Electrochemical Detection of Oral Cancer. ACS Appl. Mater. Interfaces 2017, 9, 27462-27474.

(52) Liu, B.; Zhang, B.; Cui, Y.; Chen, H.; Gao, Z.; Tang, D. Multifunctional Gold-Silica Nanostructures for Ultrasensitive Electrochemical Immunoassay of Streptomycin Residues. ACS Appl. Mater. Interfaces 2011, 3, 4668-4676.

(53) Wang, J.; Yao, H. B.; He, D.; Zhang, C. L.; Yu, S. H. Facile Fabrication of Gold Nanoparticles-Poly(Vinyl Alcohol) Electrospun Water-Stable Nanofibrous Mats: Efficient Substrate Materials for Biosensors. ACS Appl. Mater. Interfaces 2012, 4, 1963-1971.

(54) Jeong, B.; Akter, R.; Han, O. H.; Rhee, C. K.; Rahman, M. A. Increased Electrocatalyzed Performance through Dendrimer-Encapsulated Gold Nanoparticles and Carbon Nanotube-Assisted Multiple Bienzymatic Labels: Highly Sensitive Electrochemical Immunosensor for Protein Detection. Anal. Chem. 2013, 85, 1784-1791.

(55) Xiao, Y.; Ju, H. X.; Chen, H. Y. Hydrogen Peroxide Sensor Based on Horseradish Peroxidase-Labeled Au Colloids Immobilized on Gold Electrode Surface by Cysteamine Monolayer. Anal. Chim. Acta 1999, 391, 73-82.

(56) Saravanan, K.; Kumar, P. P.; Praveenraj, J.; Baruah, A.; Sivaramakrishnan, T.; Kumar, T. S.; Kumar, S. P.; Sankar, R. K.; Roy, S. D. Investigation and Confirmation of White Spot Syndrome Virus (WSSV) Infection in Wild Caught Penaid Shrimps of Andaman and Nicobar Islands, India. Virus Dis. 2017, 28, 368-372.

(57) Silveira, A. S.; Matos, G. M.; Falchetti, M.; Ribeiro, F. S.; Albert Bressan, A.; Bachere, E.; Perazzolo, L. M.; Rosa, R. D. An ImmuneRelated Gene Expression Atlas of the Shrimp Digestive System in Response to Two Major Pathogens Brings Insights into the Involvement of Hemocytes in Gut Immunity. Dev. Comp. Immunol. 2018, 79, 44-50.

(58) Koiwai, K.; Kodera, T.; Thawonsuwan, J.; Kawase, M.; Kondo, H.; Hirono, I. A Rapid Method for Simultaneously Diagnosing Four Shrimp Diseases Using PCR-DNA Chromatography Method. J. Fish Dis. 2018, 41, 395-399.

(59) Umai, A.; Ramnathan, N.; Saravanabava, K. Study by PCR on the Prevalence of White Spot Syndrome Virus, Monodon Baculovirus and Hepatopancreatic Parvovirus Infection in Penaeus monodon Post Larvae in Tamil Nadu, Southeast Coast of India. Asian Fish. Sci. 2007, 20, 227-239.

(60) Roy, C.; Chaala, A.; Darmstadt, H. The Vacuum Pyrolysis of Used Tires End-Uses for Oil and Carbon Black Products. J. Anal. Appl. Pyrolysis 1999, 51, 201-221.

(61) Laviron, E. General Expression for the Linear Potential Sweep Voltammograms in the case of Diffusionless Electrochemical Systems. J. Electroanal. Chem. Interfacial Electrochem. 1979, 101, 19-28.

(62) Gayathri, P.; Kumar, A. S. An Iron Impurity in Multiwalled Carbon Nanotube Complexes with Chitosan that Biomimics the Heme-Peroxidase Function. Chem. - Eur. J. 2013, 19, 17103-17112.

(63) Stuart, B. Infrared Spectroscopy: Fundamental and Applications; John Wiley \& Sons, 2005.

(64) Sundaram, S.; Annamalai, S. K. Selective Immobilization of Hydroquinone on Carbon Nanotube Modified Electrode via Phenol Electro-Oxidation Method and its Hydrazine Electro-catalysis and Escherichia coli Antibacterial Activity. Electrochim. Acta 2012, 62, 207-217.

(65) Liu, W.; Zhang, K.; Qin, Y.; Yu, J. A Simple and Green Ultrasonic-Assisted Liquid-Liquid Microextraction Technique Based on Deep Eutectic Solvents for the HPLC Analysis of sesamol in sesame oils. Anal. Methods 2017, 9, 4184-4189.

(66) Makino, Y.; Uchiyama, S.; Ohno, K.-I.; Arakawa, H. Low-Cost Fluorimetric Determination of Radicals Based on Fluorogenic Dimerization of the Natural Phenol Sesamol. Anal. Chem. 2010, 82, 1213-1220.

(67) Devi, K. S. D.; Jacob, S.; Kumar, A. S. In Situ Structural Elucidation and Selective $\mathrm{Pb}^{2+}$ Ion Recognition of Polydopamine Film
Formed by Controlled Electrochemical Oxidation of Dopamine. Langmuir 2018, 34, 7048-7058.

(68) de Figueiredo, R. M.; Suppo, J.-S.; Campagne, J.-M. Nonclassical Routes for Amide Bond Formation. Chem. Rev. 2016, 116, 12029-12122.

(69) Sornambikai, S.; Abdul Kadir, M. R.; Kumar, A. S.; Ponpandian, N.; Viswanathan, C. Selective and Low Potential Electrocatalytic Oxidation and Sensing of L-Cysteine Using Metal Impurity Containing Carbon Black Modified Electrode. Anal. Methods 2017, 9, 6791-6800.

(70) Liu, S.; Chen, A. Coadsorption of Horseradish Peroxidase with Thionine on $\mathrm{TiO}_{2}$ Nanotubes for Biosensing. Langmuir 2005, 21, 8409-8413.

(71) Cai, W.-Y.; Xu, Q.; Zhao, X.-N.; Zhu, J.-J.; Chen, H.-Y. Porous Gold-Nanoparticle- $\mathrm{CaCO}_{3}$ Hybrid Material: Preparation, Characterization, and Application for Horseradish Peroxidase Assembly and Direct Electrochemistry. Chem. Mater. 2006, 18, 279-284.

(72) Yang, S.; Jia, W.-Z.; Qian, Q.-Y.; Zhou, Y.-G.; Xia, X.-H. Simple Approach for Efficient Encapsulation of Enzyme in Silica Matrix with Retained Bioactivity. Anal. Chem. 2009, 81, 3478-3484. 